TITLE:

\title{
Singly and doubly excited states of butadiene, acrolein, and glyoxal: Geometries and electronic spectra
}

\section{AUTHOR(S):}

Saha, B; Ehara, M; Nakatsuji, H

\section{CITATION:}

Saha, B ...[et al]. Singly and doubly excited states of butadiene, acrolein, and glyoxal: Geometries and electronic spectra. JOURNAL OF CHEMICAL PHYSICS 2006, 125(1): 014316.

ISSUE DATE:

2006-07-01

URL:

http://hdl.handle.net/2433/50106

\section{RIGHT:}

Copyright 2006 American Institute of Physics. This article may be downloaded for personal use only. Any other use requires prior permission of the author and the American Institute of Physics. 


\title{
Singly and doubly excited states of butadiene, acrolein, and glyoxal: Geometries and electronic spectra
}

\author{
Biswajit Saha and Masahiro Ehara ${ }^{a}$ \\ Department of Synthetic Chemistry and Biological Chemistry, Graduate School of Engineering, \\ Kyoto University, Katsura, Nishikyo-ku, Kyoto 615-8510, Japan \\ Hiroshi Nakatsuji ${ }^{\text {a) }}$ \\ Department of Synthetic Chemistry and Biological Chemistry, Graduate School of Engineering, \\ Kyoto University, Katsura, Nishikyo-ku, Kyoto 615-8510, Japan and Fukui Institute for Fundamental \\ Chemistry, Kyoto University, 34-4 Takano Nishihirakicho, Sakyo-ku, Kyoto 606-8103, Japan
}

(Received 18 November 2005; accepted 4 April 2006; published online 7 July 2006)

Excited-state geometries and electronic spectra of butadiene, acrolein, and glyoxal have been investigated by the symmetry adapted cluster configuration interaction (SAC-CI) method in their s-trans conformation. Valence and Rydberg states below the ionization threshold have been precisely calculated with sufficiently flexible basis sets. Vertical and adiabatic excitation energies were well reproduced and the detailed assignments were given taking account of the second moments. The deviations of the vertical excitation energies from the experiment were less than $0.3 \mathrm{eV}$ for all cases. The SAC-CI geometry optimization has been applied to some valence and Rydberg excited states of these molecules in the planar structure. The optimized ground- and excited-state geometries agree well with the available experimental values; deviations lie within $0.03 \AA$ and $0.7^{\circ}$ for the bond lengths and angles, respectively. The force acting on the nuclei caused by the excitations has been discussed in detail by calculating the SAC-CI electron density difference between the ground and excited states; the geometry relaxation was well interpreted with the electrostatic force theory. In Rydberg excitations, geometry changes were also noticed. Doubly excited states (so-called $2{ }^{1} A_{g}$ states) were investigated by the SAC-CI general- $R$ method considering up to quadruple excitations. The characteristic geometrical changes and large energetic relaxations were predicted for these states. (C) 2006 American Institute of Physics.

[DOI: $10.1063 / 1.2200344]$

\section{INTRODUCTION}

The investigations of the spectroscopy and photochemistry of conjugated molecules are unabated in order to clarify the role of conjugation and the electronic properties of their excited states have been of considerable interest for many years. For understanding the spectroscopic properties of $\pi$-conjugated molecules, electronic spectra of butadiene, acrolein, and glyoxal are fundamental and an important subject. Therefore, various experimental techniques were applied to characterize the electronic excited states of these molecules. The UV absorption spectra of glyoxal and acrolein were first reported by Walsh and co-workers. ${ }^{1-3}$ Later on, electron impact excitation, ${ }^{4}$ electron energy loss spectroscopy (EELS), ${ }^{5-7}$ UV absorption spectra, ${ }^{8-10}$ resonance Raman scattering spectroscopy ${ }^{11}$ methods were applied to these molecules. However, in some cases, contradictory results were obtained; for example, in trans-butadiene, resonance Raman scattering study showed that $1{ }^{1} B_{u}$ state is energetically higher than $2{ }^{1} A_{g}$ state, whereas multiphoton ionization (MPI) or EELS experiments reported the reverse order. Many theoretical works have also been performed to investigate the electronic spectra of these molecules. ${ }^{12-29} \mathrm{Ab}$ initio

\footnotetext{
${ }^{a)}$ Authors to whom correspondence should be addressed. Electronic mails: ehara@sbchem.kyoto-u.ac.jp and hiroshi@sbchem.kyoto-u.ac.jp
}

methods such as the symmetry adapted cluster configuration interaction (SAC-CI) ${ }^{16}$ complete active space perturbation theory to second order (CASPT2), ${ }^{21,22}$ multireference Moller-Plesset (MRMP), ${ }^{23}$ and multireference configuration interaction $^{24,25}$ (MRCI) were utilized to calculate the vertical excitation energies of these molecules. In the recent years, the low-lying excited states of trans-1,3-butadiene were intensively examined, in particular, the $2{ }^{1} A_{g}$ and $1{ }^{1} B_{u}$ excited states by MRCI with singles and doubles (MR-CISD) and multireference averaged quadratic coupled cluster (MRAQCC) methods ${ }^{30}$ and the $2{ }^{1} A_{g}$ excited state by using a variety of $a b$ initio methods, complete active space selfconsistent field (CASSCF), CASPT2, multireference singles and doubles configuration interaction (MRSDCI), and quasidegenerate variational perturbation theory (QDVPT) ${ }^{31}$

The geometry relaxation in the excited states is of special interest, since the excited-state geometries are responsible for the shape of the absorption spectra as well as the emission spectra. Accurate theoretical investigation on the excited-state geometries has become possible..$^{24,27,29}$ For the present $4 \pi$-electron systems, some theoretical works were reported for the stable geometries of the low-lying valence excited states. However, the analytical energy gradients are not so common to the highly correlated methods which describe both static and dynamics correlations. Among corre- 
lated methods, SAC-CI, ${ }^{32,33}$ restricted active space selfconsistent field (RASSCF), ${ }^{29}$ and $\mathrm{MRCI}^{34}$ energy gradients are available. Therefore, further methodological developments and extensive applications for the excited-state geometries are expected.

For 1,3-butadiene, many theoretical works have been performed for the electronic spectra. Kitao and Nakatsuji ${ }^{16}$ studied the valence and low-lying Rydberg states in both trans and cis forms by using the SAC-CI method. They investigated the vertical excitations and gave the reliable assignments for the optically allowed ${ }^{1} B_{u}$ states. They showed that both $\sigma$ - and $\pi$-electron correlations are important for calculating the various excitations. Calculation by means of linear and quadratic response theories also has been performed for the low-lying levels of this molecule. ${ }^{35}$ Recently, second order multireference perturbation theory using an optimized partitioning (MROPT2) was applied to calculate the excited states of butadiene and other molecules. ${ }^{28}$ The excited-state geometries of the valence exited states of this molecule were also investigated. Szalay et al. studied the planar and nonplanar structures with multiconfiguration selfconsistent field (MCSCF) ${ }^{24}$ Boggio-Pasqua et al. performed the RASSCF calculation to examine the geometries of the ionic and covalent excited states of butadiene. ${ }^{29}$

For acrolein, valence and Rydberg excited states of $\mathrm{cis}$ and trans-acrolein were recently investigated by using CASPT2 and time-dependent density functional theory (TDDFT) methods. ${ }^{27}$ Accurate assignments were proposed comparing with the experimental results. They also studied the solvent effect of this molecule in aqueous solution. Although the excitation energies estimated by the CASPT2 and TDDFT methods agree well, the oscillator strength values differ among these calculations. For some transitions, differences were also found in the excitation energies between the CASPT2 and multistate CASPT2 (MS-CASPT2) calculations. They also studied the geometry relaxation of three lowest valence excited states with unconstrained geometry optimizations.

For glyoxal, the SAC-CI method with direct-type algorithm was applied to the singlet and triplet excited states. ${ }^{19}$ The adiabatic excitations were also examined and the agreements with the experimental values were encouraging. The excitation energies for this molecule estimated by the $\mathrm{SCF}^{26}$ $\mathrm{CI}^{20}{ }^{20}$ and CASSCF (Ref. 36) calculations are also available for some low-lying excited states; however, the agreement with the experimental values was not good. For this molecule, the electron correlations were found to be important for reproducing the order of the $n^{+}, n^{-}, \pi_{\mathrm{C}=\mathrm{O}^{-}}$and $\pi_{\mathrm{C}=\mathrm{O}^{+}}$ valence ionized states, ${ }^{26,37,38}$ and therefore sufficient electron correlations should be evaluated for the accurate calculations of the excited states.

The SAC-CI method ${ }^{39,40}$ has firmed its applicability in the wide varieties of subjects in chemistry and physics, such as in molecular spectroscopy, biological photochemistry, and surface chemistry. ${ }^{41}$ The analytical energy gradients of the SAC-CI method are available for various kinds of electronic states. ${ }^{32,33,42}$ The method is useful for studying the excitedstate geometries, dipole moments, and vibrational frequen- cies of molecules. In this work, we applied the SAC-CI method to the accurate assignments of the electronic spectra of s-trans 1,3-butadiene, s-trans acrolein, and s-trans glyoxal up to high energy region and to the investigation of the excited-state geometries of these molecules. The $\sigma$ - and $\pi$-electron correlations which are crucial for the proper description of the ionic and covalent excited states can be well described by the SAC-CI method. By calculating the electron density difference between the ground and excited states with the SAC-CI method, the geometry relaxations in the excited states were discussed based on the electrostatic force (ESF) theory proposed by Nakatsuji. ${ }^{43}$

\section{COMPUTATIONAL DETAILS}

The excitation energy and the excited-state geometries for the singlet and triplet excited states were calculated. For calculating the vertical excitations, the double-zeta basis sets due to Huzinaga/Dunning ${ }^{44}$ plus one polarization $[4 s 2 p 1 d / 2 s]$ were adopted with double-zeta Rydberg functions for describing $3 s 3 p 3 d(2 s 2 p 2 d)$ and $4 s 4 p$ orbitals $[2 s 2 p]$ (Ref. 45) for butadiene and glyoxal, and $3 s 3 p 3 d$ $(2 s 2 p 2 d)$ orbitals for acrolein. Hence, the numbers of atomic orbitals (AOs) were 188, 152, and 180 for butadiene, acrolein, and glyoxal, respectively. The $1 s$ orbitals of first-row atoms and their counterpart molecular orbitals are kept fixed and excluded from the active space, and therefore the active spaces for calculating the vertical spectra are 172, 136, and 164 molecular orbitals (MOs).

For the excited-state geometry calculations, we included the $3 s 3 p$ Rydberg functions [2s2p] (Ref. 45) along with DZ1P basis for all these three molecules. The minimumorbital deformation (MOD) method with frozen-core orbitals was adopted in the SAC-CI geometry optimization. Therefore, the active spaces used in the geometry optimization step are 11 occupied MOs for each molecule and 89, 85, and 81 unoccupied MOs for 1,3-butadiene, acrolein, and glyoxal, respectively.

Since the present valence and Rydberg excited states are dominantly described by single excitations, we used the SD- $R$ calculations. To reduce the computational effort, the perturbation selection scheme was adopted. ${ }^{46}$ The LevelThree accuracy was adopted to calculate the large number of excited states accurately. The threshold of the linked terms for the ground state was set to $\lambda_{g}=1.0 \times 10^{-6}$. The unlinked terms were described as the product of the linked operators with SDCI coefficients larger than 0.005. For excited states, the threshold of the linked doubles was set to $\lambda_{e}=1.0$ $\times 10^{-7}$. The thresholds of the CI coefficients for calculating the unlinked operators were 0.05 and 0.00 for the $R$ and $S$ operators, respectively.

The SAC-CI geometry optimization was performed with the CI-singles (CIS) optimized parameters as the initial geometry. The initial geometries of CIS calculations were due to experimental ones. ${ }^{47}$ The geometry optimizations were restricted to planar structures for all molecules. The SAC-CI general- $R$ calculations, ${ }^{33,48}$ including up to quadruple excitations, were also performed for estimating vertical excitation energies and optimized geometries of the doubly excited 
TABLE I. Vertical excitation energy $(\Delta E$ in $\mathrm{eV})$, oscillator strength $(f)$, and the electronic part of second moment $\left(\left\langle r^{2}\right\rangle\right.$ in a.u.) of s-trans 1,3-butadiene for various singlet transitions using $[4 s 2 p 1 d / 2 s]+[2 s 2 p 2 d](n=3)+[2 s 2 p](n=4)$ basis set.

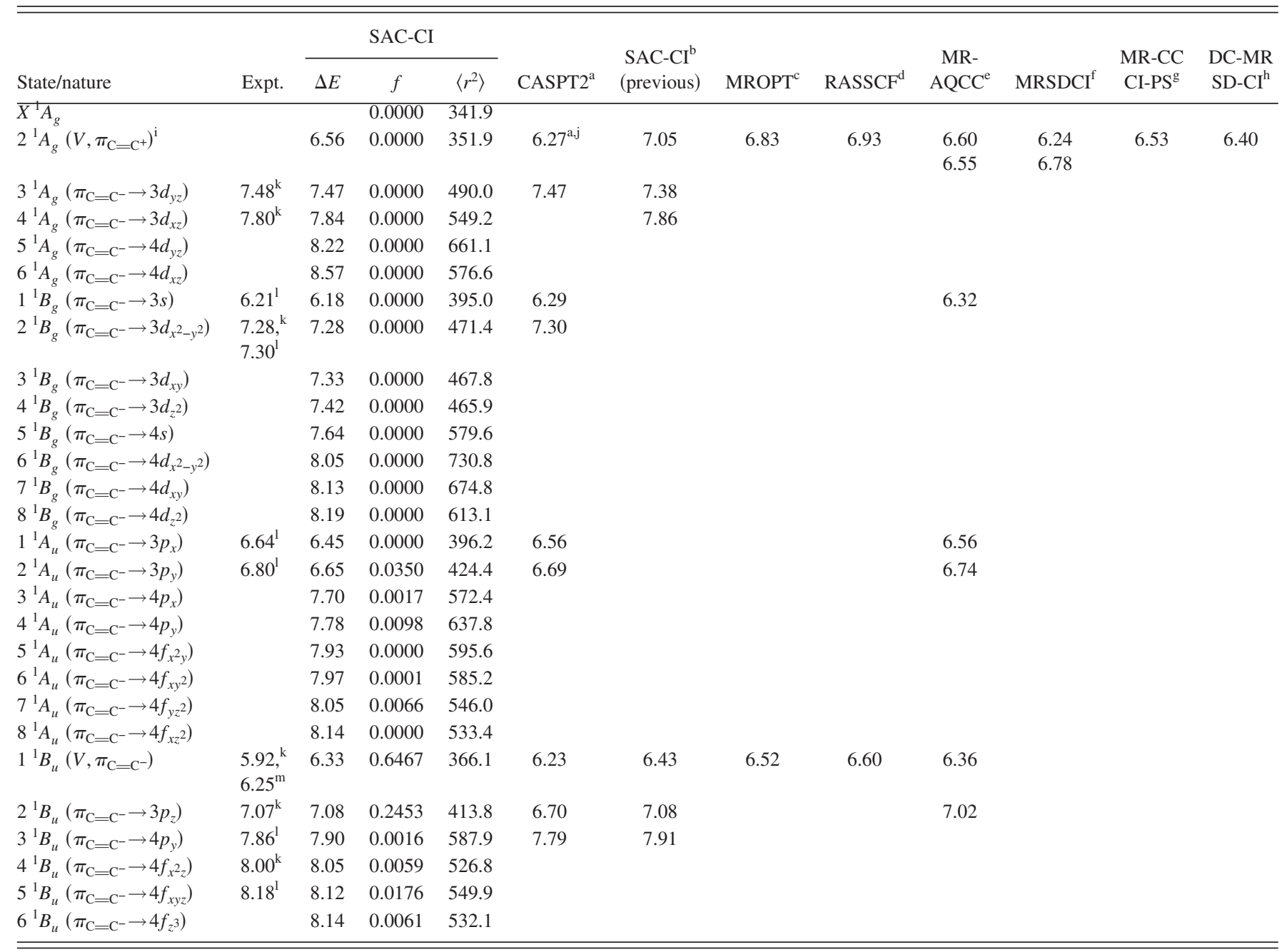

${ }^{\mathrm{a}}$ Reference 21 .

${ }^{\mathrm{b}}$ Reference 16.

${ }^{\mathrm{c}}$ Reference 28.

${ }^{\mathrm{d}}$ Reference 29.

${ }^{\mathrm{e}}$ Reference 30.

${ }^{\mathrm{f}}$ References 24 and 25.

${ }^{g}$ Reference 55.

states. The GAUSSIAN 03 suite of programs ${ }^{49}$ has been utilized for the SAC-CI calculations. Interested readers may glean much information from the articles ${ }^{41}$ and references therein.

\section{ELECTRONIC SPECTRA OF S-TRANS 1,3-BUTADIENE}

In this section, we first discuss the valence and Rydberg excited states of s-trans 1,3-butadiene. The SAC-CI results of the singlet and triplet excited states are summarized for the vertical excitations in Tables I and II, respectively, with the experimental and other theoretical values. The calculated ionization threshold is $8.80 \mathrm{eV}$ with the present basis set in comparison with the experimental one, $9.09 \mathrm{eV}{ }^{50}$ The deviations of the vertical excitation energies from the experimental values are less than $0.3 \mathrm{eV}$ in all cases. For the single photon process, the transitions to $A_{u}$ or $B_{u}$ states are optically allowed and the transitions to $g$-symmetry state are forbidden.

\author{
${ }^{\mathrm{h}}$ Reference 31. \\ ${ }^{i}$ SAC-CI general- $R$ calculation. \\ ${ }^{\mathrm{j}}$ Reference 51. \\ ${ }^{\mathrm{k}}$ References 4-6. \\ ${ }^{\mathrm{l}}$ References 9 and 53. \\ ${ }^{\mathrm{m}}$ Reference 10 .
}

Strong absorption for the $1{ }^{1} B_{u}$ state was observed experimentally at $6.25 \mathrm{eV},{ }^{10}$ which is $0.08 \mathrm{eV}$ lower than our value of $6.33 \mathrm{eV}$. Other theoretical values for this transition are $6.60 \mathrm{eV}$ (Ref. 29) (RASSCF), $6.23 \mathrm{eV},{ }^{21,22} 6.06 \mathrm{eV}$ (Ref. 51) (CASPT2), $5.90 \mathrm{eV}$ (Ref. 52) (TDDFT), and $6.18 \mathrm{eV}$ (Ref. 30) (MR-AQCC). Thus most of the recent theoretical values are converging at $6.2 \mathrm{eV}$ for this ionic state. From the SD- $R$ calculations, we found that the contributions of doubly excited configurations were significant to the $2{ }^{1} A_{g}$ state. Hence, for this state, we performed the SAC-CI general- $R$ calculations and obtained a value of $6.56 \mathrm{eV}$. This state, as reported by Doering and McDiarmid, ${ }^{9,53}$ is of valence character, which corroborates our result. Some experiments have assigned this state at quite low energy, ranging from a value of 5.4 to $5.8 \mathrm{eV}$. $^{11,54}$ The EELS experiment reported a value of $7.08 \mathrm{eV}$ (Ref. 4) or $7.3 \mathrm{eV}$ (Refs. 5 and 9) for this state. Our value is in good agreement with the value $(6.53 \mathrm{eV})$ obtained by the MR consistent correlation CI perturbation 
TABLE II. Vertical excitation energy $(\Delta E$ in $\mathrm{eV})$ and the electronic part of second moment $\left(\left\langle r^{2}\right\rangle\right.$ in a.u.) of s-trans 1,3-butadiene for triplet transitions by the SAC-CI method with $[4 s 2 p 1 d / 2 s]+[2 s 2 p 2 d](n=3)+[2 s 2 p](n=4)$ basis set.

\begin{tabular}{|c|c|c|c|c|c|}
\hline \multirow[b]{2}{*}{ State/nature } & \multirow[b]{2}{*}{ Expt. $^{a, b}$} & \multicolumn{2}{|c|}{ SAC-CI } & \multirow[b]{2}{*}{$\mathrm{MRCI}^{\mathrm{c}}$} & \multirow{2}{*}{$\begin{array}{l}\mathrm{SAC}^{\mathrm{S}-\mathrm{CI}^{\mathrm{d}}} \\
\text { (previous) }\end{array}$} \\
\hline & & $\Delta E$ & $\left\langle r^{2}\right\rangle$ & & \\
\hline $1{ }^{3} A_{g}\left(V, \pi_{\mathrm{C}=\mathrm{C}^{+}}\right)$ & 4.91 & 5.08 & 344.1 & 4.95 & 5.15 \\
\hline $2{ }^{3} A_{g}\left(\pi_{\mathrm{C}=\mathrm{C}^{-}} \rightarrow 3 s\right)$ & & 7.36 & 444.2 & & 7.22 \\
\hline $3{ }^{3} A_{g}^{g}\left(\pi_{\mathrm{C}=\mathrm{C}^{-}} \rightarrow 3 d_{y z}\right)$ & & 7.42 & 474.7 & & 7.26 \\
\hline $4{ }^{3} A_{g}\left(\pi_{\mathrm{C}=\mathrm{C}^{-}} \rightarrow 3 d_{x z}\right)$ & & 7.99 & 477.2 & & \\
\hline $5^{3} A_{g}\left(\pi_{\mathrm{C}=\mathrm{C}^{-}} \rightarrow 4 d_{y z}\right)$ & & 8.17 & 590.1 & & \\
\hline $6{ }^{3} A_{g}^{g}\left(\pi_{\mathrm{C}=\mathrm{C}^{-}} \rightarrow 4 d_{x z}\right)$ & & 8.57 & 655.1 & & \\
\hline $1{ }^{3} B_{g}^{8}\left(\pi_{\mathrm{C}=\mathrm{C}^{-}} \rightarrow 3 s\right)$ & & 6.14 & 393.4 & 6.17 & \\
\hline $2{ }^{3} B_{g}\left(\pi_{\mathrm{C}=\mathrm{C}^{-}} \rightarrow 3 d_{x^{2}-y^{2}}\right)$ & & 7.26 & 470.2 & 7.29 & \\
\hline $3{ }^{3} B_{g}^{s}\left(\pi_{\mathrm{C}=\mathrm{C}^{-}} \rightarrow 3 d_{x y}\right)$ & & 7.32 & 464.0 & & \\
\hline $4{ }^{3} B_{g}^{\delta}\left(\pi_{\mathrm{C}=\mathrm{C}^{-}} \rightarrow 3 d_{z^{2}}\right)$ & & 7.40 & 464.2 & & \\
\hline $5^{3} B_{g}^{8}\left(\pi_{\mathrm{C}=\mathrm{C}^{-}} \rightarrow 4 s\right)$ & & 7.62 & 576.2 & & \\
\hline $6{ }^{3} B_{g}\left(\pi_{\mathrm{C}=\mathrm{C}^{-}} \rightarrow 4 d_{x^{2}-y^{2}}\right)$ & & 8.04 & 728.8 & & \\
\hline $7{ }^{3} B_{g}^{8}\left(\pi_{\mathrm{C}=\mathrm{C}^{-}} \rightarrow 4 d_{x y}\right)$ & & 8.12 & 670.2 & & \\
\hline $8^{3} B_{g}^{6}\left(\pi_{\mathrm{C}=\mathrm{C}^{-}} \rightarrow 4 d_{z^{2}}\right)$ & & 8.16 & 617.9 & & \\
\hline $1{ }^{3} A_{u}\left(\pi_{\mathrm{C}=\mathrm{C}^{-}} \rightarrow 3 p_{x}\right)$ & & 6.45 & 396.5 & 6.48 & \\
\hline $2^{3} A_{u}\left(\pi_{\mathrm{C}=\mathrm{C}^{-}} \rightarrow 3 p_{y}\right)$ & 6.81 & 6.61 & 421.3 & 6.67 & \\
\hline $3{ }^{3} A_{u}\left(\pi_{\mathrm{C}=\mathrm{C}^{-}} \rightarrow 4 p_{x}\right)$ & & 7.69 & 565.3 & & \\
\hline $4{ }^{3} A_{u}\left(\pi_{\mathrm{C}=\mathrm{C}^{-}} \rightarrow 4 p_{y}\right)$ & & 7.76 & 558.0 & & \\
\hline $5^{3} A_{u}\left(\pi_{\mathrm{C}=\mathrm{C}^{-}} \rightarrow 4 f_{x^{2} y}\right)$ & & 7.77 & 429.2 & & \\
\hline $6^{3} A_{u}\left(\pi_{\mathrm{C}=\mathrm{C}^{-}} \rightarrow 4 f_{x y^{2}}\right)$ & & 7.92 & 592.9 & & \\
\hline $7^{3} A_{u}\left(\pi_{\mathrm{C}=\mathrm{C}^{-}} \rightarrow 4 f_{y z^{2}}\right)$ & & 7.97 & 586.6 & & \\
\hline $8^{3} A_{u}\left(\pi_{\mathrm{C}=\mathrm{C}^{-}} \rightarrow 4 f_{x z^{2}}\right)$ & & 8.04 & 542.6 & & \\
\hline $1^{3} B_{u}\left(V, \pi_{\mathrm{C}=\mathrm{C}^{-}}\right)$ & 3.22 & 3.20 & 342.5 & 3.24 & 3.48 \\
\hline $2{ }^{3} B_{u}\left(\pi_{\mathrm{C}=\mathrm{C}^{-}} \rightarrow 3 p_{z}\right)$ & & 6.79 & 418.0 & 7.55 & 6.65 \\
\hline $3{ }^{3} B_{u}\left(\pi_{\mathrm{C}=\mathrm{C}^{-}} \rightarrow 4 p_{z}\right)$ & & 7.89 & 584.8 & 7.92 & 7.83 \\
\hline $4^{3} B_{u}\left(\pi_{\mathrm{C}=\mathrm{C}^{-}} \rightarrow 4 f_{x^{2} z}\right)$ & & 8.03 & 561.7 & & \\
\hline $5^{3} B_{u}\left(\pi_{\mathrm{C}=\mathrm{C}^{-}} \rightarrow 4 f_{x y z}\right)$ & & 8.06 & 524.8 & & \\
\hline $6^{3} B_{u}\left(\pi_{\mathrm{C}=\mathrm{C}^{-}} \rightarrow 4 f_{z^{3}}\right)$ & & 8.13 & 522.4 & & \\
\hline
\end{tabular}

${ }^{\mathrm{a}}$ References 4-6. $\quad{ }^{\mathrm{c}}$ Reference 17.

${ }^{\mathrm{b}}$ Reference $2 . \quad{ }^{\mathrm{d}}$ Reference 16.

selected (MR-CCCI-PS), ${ }^{55}$ and $6.40 \mathrm{eV}$ of DC-MRSDCI (Ref. 31) and $6.55 \mathrm{eV}$ of MR-AQCC calculations. ${ }^{30} \mathrm{MROPT}$ (Ref. 28) calculation estimated this state at $6.83 \mathrm{eV}$, MRSDCI estimated value of $6.77 \mathrm{eV},{ }^{25}$ and CASPT2 calculation reported a value of $6.27 \mathrm{eV} .^{21}$ The CASPT2 tends to predict low excitation energy, especially for the doubly excited states.

Analyzing the electronic part of the second moment $\left\langle r^{2}\right\rangle$, we found that both the $1{ }^{1} B_{u}$ state with $\left\langle r^{2}\right\rangle=366.1$ a.u. and the $2{ }^{1} A_{g}$ state with $\left\langle r^{2}\right\rangle=351.9$ a.u. have purely valence character as reported in the previous studies. By including $\sigma$ - and $\pi$-electron correlations, reliable values of $\left\langle r^{2}\right\rangle$ can be obtained for these ionic and covalent states. The $z$ component of the second moment was calculated to be $\left\langle z^{2}\right\rangle$ $=35.5$ a.u. for the $1{ }^{1} B_{u}$ state and $\left\langle z^{2}\right\rangle=73.0$ a.u. for the $2{ }^{1} B_{u}$ state. In the previous SAC-CI calculation, ${ }^{16}$ these values were $\left\langle z^{2}\right\rangle=44$ and 65 a.u., for the $1{ }^{1} B_{u}$ and $2{ }^{1} B_{u}$ states, respectively. Kitao and Nakatsuji ${ }^{16}$ showed that $\pi$ - and $\sigma$-electron correlations are important for the ionic valence excited states of trans-butadiene and the wave function of the ionic valence excited state expands like a Rydberg state without $\sigma$-electron correlations. In the present calcula- tion, therefore, the $\sigma$-electron correlation was also well described.

We obtained the ionic $1{ }^{1} B_{u}$ state energetically lower than the covalent $2{ }^{1} A_{g}$ state which is supported by most of the previous computations and experiments. The oscillator strength was calculated to be 0.65 for the $1{ }^{1} B_{u}$ state in comparison with the observed ${ }^{56}$ value $(\approx 0.4)$ and the previous SAC-CI (Ref. 16) value (0.47) showed quite good agreement. The present oscillator strength is in good agreement with the CASCI value of 0.69 of Serrano-Andres et al. ${ }^{21}$ It differs, however, by an order from the corresponding value of 0.07 by Buenker et al. ${ }^{57}$ with MRCI. The oscillator strength of 0.245 for the $2{ }^{1} B_{u}$ state agrees well with the previous SAC-CI (Ref. 16) value of 0.234 .

Next, we discuss the Rydberg excited states, which are calculated in high accuracy by the SAC-CI method. As compared in Tables I and II, the present results agree very well with the experimental values. We calculated the $2{ }^{1} B_{u}$ state at $7.08 \mathrm{eV}$ as $\pi_{\mathrm{C}=\mathrm{C}^{-}} \rightarrow 3 p_{z}$ Rydberg transition which agrees very well with the experimental value, $7.07 \mathrm{eV} .{ }^{4-6}$ Other $3 p$ Rydberg transitions were obtained at 6.45 and $6.65 \mathrm{eV}$ in $A_{u}$ symmetry, for $x$ and $y$ components, respectively, whose oscillator strengths are small. Rydberg $3 s$ state, $1{ }^{1} B_{g}$, was calculated to be $6.18 \mathrm{eV}$, in good agreement with the experimental value of $6.21 \mathrm{eV}{ }^{9,53}$ Transitions to $3 d$ Rydberg states are all dipole forbidden, $A_{g}$ and $B_{g}$ states, and they were calculated in the energy region of $7.28-7.84 \mathrm{eV}$ above the ground state. The $3 d_{x^{2}-y^{2}}, 3 d_{y z}$, and $3 d_{x z}$ states were calculated to be $7.28,7.47$, and $7.84 \mathrm{eV}$, in comparison with the experimental $^{4-6}$ values of $7.28,7.48$, and $7.80 \mathrm{eV}$, respectively.

For the transitions to $n=4$, Rydberg $4 s, 4 p$, and $4 d$ states were obtained in the energy regions of 7.64, 7.70-7.90, and $8.05-8.57 \mathrm{eV}$, respectively. Since the Rydberg functions of lower angular momentum was placed on each carbon, Rydberg $4 f$ states were described in the present calculation. We also confirmed the present assignment by other SAC-CI calculations with $4 f$ Rydberg function placed on the center of molecule. Experimentally, Doering and McDiarmid ${ }^{9}$ reported an optically allowed Rydberg $(4 f)$ transition at $8.18 \mathrm{eV}$. We have assigned this transition to $\pi_{\mathrm{C}=\mathrm{C}} \rightarrow 4 f_{x y z}$ state calculated at $8.12 \mathrm{eV}$.

Now, we discuss the triplet excited states corresponding to the singlet excited states for which we performed calculations. The lowest two triplet states, i.e., $1{ }^{3} B_{u}$ and $1{ }^{3} A_{g}$, were observed experimentally ${ }^{4,5}$ and the theoretical results show good agreement with the experiment; the present values are 3.20 and $5.08 \mathrm{eV}$, in comparison with the experimental values of 3.22 and $4.91 \mathrm{eV}$, respectively. For the triplet Rydberg states, Price and Walsh ${ }^{2}$ reported the transition at $6.81 \mathrm{eV}$, which was assigned to the $\pi_{\mathrm{C}=\mathrm{C}^{-}} \rightarrow 3 s$ Rydberg transition. For this transition, we calculated the $3 p_{y}$ triplet excited state $\left(2{ }^{3} A_{u}\right.$ state $)$ at $6.61 \mathrm{eV}$. The CI calculation performed by Shih et al. ${ }^{17}$ reported a value of $6.67 \mathrm{eV}$ for the same transition, which agrees well with the present values. Our assignment of $\pi_{\mathrm{C}=\mathrm{C}^{-}} \rightarrow 3 p_{z}$ for the $2{ }^{3} B_{u}$ state also corroborates the previous SAC-CI assignment $3 p \pi$ by Kitao and Nakatsuji, ${ }^{16}$ the excitation energy differs by an amount of $0.14 \mathrm{eV}$. 

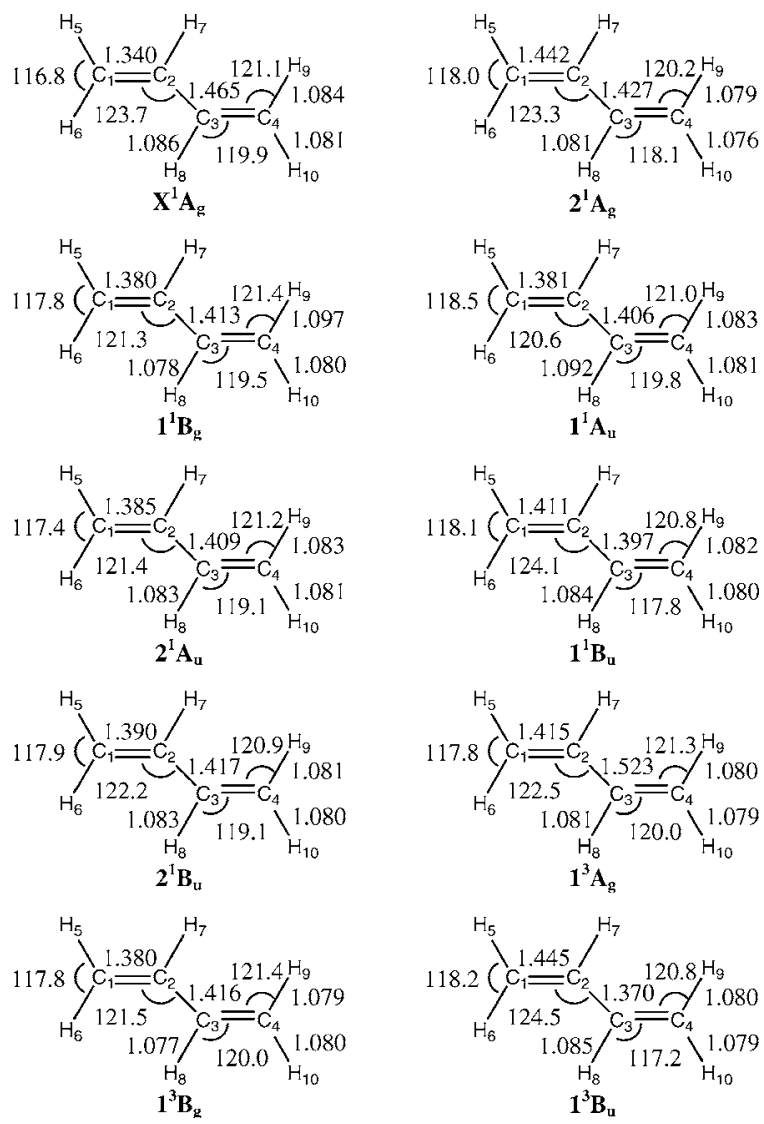

FIG. 1. Geometries for the ground and excited states of s-trans 1,3butadiene optimized by the SAC-CI method. Bond lengths and angles are in $\AA$ and degree, respectively.

\section{GROUND- AND EXCITED-STATE GEOMETRIES OF S-TRANS 1,3-BUTADIENE}

The equilibrium geometries for the ground and some excited states of butadiene optimized by the SAC-CI method are displayed in Fig. 1. The ground state of trans-butadiene has the planar $C_{2 h}$ structure and the excited-state geometries are examined with restricting the $C_{2 h}$ structure, though nonplanar structures were reported to be stable in some excited states. ${ }^{29}$ Recently, it was reported that the $T_{1}\left(1^{3} B_{u}\right)$ state of butadiene has planar structure. ${ }^{58}$ In Table III, we summarized the comparison of the $\mathrm{C}-\mathrm{C}$ bond length and $\mathrm{CCC}$ bond angles with the experimental and other theoretical values. The adiabatic transition energies are given in Table IV.

The optimized ground-state geometry is in excellent agreement with the experimental one. ${ }^{47}$ The terminal $\mathrm{C}_{1}=\mathrm{C}_{2}$ bond length is deviated by only $0.005 \AA$ from the experimental value and we got the same $\mathrm{C}_{2}-\mathrm{C}_{3}$ bond length as the experimental one. The RASSCF calculation ${ }^{29}$ showed deviations of 0.011 and $0.003 \AA$ for $\mathrm{C}_{1}=\mathrm{C}_{2}$ and $\mathrm{C}_{2}-\mathrm{C}_{3}$ bond lengths, respectively, while the CASPT2 (Ref. 59) estimation deviates by 0.008 and $0.011 \AA$. The CCC bond angle in the present study shows the deviation of $0.5^{\circ}$ from the experimental value.

For the excited states, planar $C_{2 h}$ structure is interesting to examine the large geometrical change, although stable nonplanar structures were found in some excited states, for example, the $\mathrm{C}_{2}$ structure was found to be a minimum in the

TABLE III. Comparison of optimized geometries for s-trans 1,3-butadiene using $[4 s 2 p 1 d / 2 s]+[2 s 2 p](n=3)$ basis set. Bond length and angle are in $\AA$ and degree, respectively.

\begin{tabular}{|c|c|c|c|c|}
\hline State/nature & Method & $\mathrm{C}=\mathrm{C}$ & $\mathrm{C}-\mathrm{C}$ & $\angle \mathrm{CCC}$ \\
\hline \multirow[t]{4}{*}{$X^{1} A_{g}$} & SAC-CI & 1.340 & 1.465 & 123.8 \\
\hline & Expt. $^{a}$ & 1.345 & 1.465 & 123.3 \\
\hline & RASSCF $^{\mathrm{b}}$ & 1.351 & 1.468 & 123.9 \\
\hline & $\mathrm{CASPT}^{\mathrm{c}}$ & 1.348 & 1.454 & 123.6 \\
\hline \multirow[t]{3}{*}{$2{ }^{1} A_{g}\left(V, \pi_{\mathrm{C}=\mathrm{C}^{+}}\right)$} & SAC-CI ${ }^{\mathrm{d}}$ & 1.442 & 1.427 & 123.3 \\
\hline & RASSCF $^{\mathrm{b}}$ & 1.501 & 1.421 & 123.0 \\
\hline & CASPT2 $^{\mathrm{c}}$ & 1.499 & 1.418 & 123.4 \\
\hline \multirow[t]{3}{*}{$1{ }^{1} B_{u}\left(V, \pi_{\mathrm{C}=\mathrm{C}^{-}}\right)$} & SAC-CI & 1.411 & 1.397 & 124.1 \\
\hline & RASSCF $^{\mathrm{b}}$ & 1.414 & 1.495 & 122.2 \\
\hline & $\mathrm{CASPT}^{\mathrm{c}}$ & 1.421 & 1.399 & 124.1 \\
\hline \multirow[t]{2}{*}{$1^{3} B_{u}\left(V, \pi_{\mathrm{C}=\mathrm{C}^{-}}\right)$} & SAC-CI & 1.445 & 1.370 & 124.5 \\
\hline & $\mathrm{MCQR}^{\mathrm{e}}$ & 1.457 & 1.361 & 124.3 \\
\hline \multirow[t]{2}{*}{$1{ }^{3} A_{g}\left(V, \pi_{\mathrm{C}=\mathrm{C}^{+}}\right)$} & SAC-CI & 1.415 & 1.523 & 122.5 \\
\hline & $\mathrm{MCQR}^{\mathrm{e}}$ & 1.435 & 1.477 & 122.9 \\
\hline
\end{tabular}

${ }^{\mathrm{a}}$ Reference 47.

${ }^{\mathrm{b}}$ Reference 29.

${ }^{\mathrm{c}}$ Reference 59.

${ }^{\mathrm{d}} \mathrm{SAC}-\mathrm{CI}$ general- $R$ calculation.

${ }^{\mathrm{e}}$ Reference 77 .

RASSCF work by Boggio-Pasqua et al. ${ }^{29}$ For the doubly excited valence $2{ }^{1} A_{g}$ state, we performed the SAC-CI general- $R$ optimization. For this state $\mathrm{C}=\mathrm{C}$ bond length increases by $0.102 \AA$ and the $\mathrm{C}-\mathrm{C}$ bond length decreases by $0.035 \AA$. The $\mathrm{C}=\mathrm{C}$ bond length is deviated by $\sim 0.059 \AA$ from that of the CASPT2 $(1.501 \AA)$ and RASSCF $(1.499 \AA)$ estimations. ${ }^{29}$ But the $\mathrm{C}-\mathrm{C}$ bond length and $\angle \mathrm{CCC}$ show good agreement.

Noticeable elongations by $0.071,0.105$, and $0.075 \AA$ of the $\mathrm{C}_{1}=\mathrm{C}_{2}$ bond length were calculated for the other va-

TABLE IV. Adiabatic and vertical excitation energy (in eV) for excited states of s-trans 1,3-butadiene using $[4 s 2 p 1 d / 2 s]+[2 s 2 p](n=3)$ basis set.

\begin{tabular}{|c|c|c|c|}
\hline State/nature & Method & Vertical & Adiabatic \\
\hline \multirow[t]{5}{*}{$2{ }^{1} A_{g}\left(V, \pi_{\mathrm{C}=\mathrm{C}^{+}}\right)$} & $\mathrm{SAC}-\mathrm{CI}^{\mathrm{a}}$ & 6.56 & 5.38 \\
\hline & CASSCF $^{\mathrm{b}}$ & 6.63 & 5.30 \\
\hline & CASPT2 $^{\mathrm{b}}$ & 6.25 & 5.02 \\
\hline & RASSCF $^{\mathrm{c}}$ & 6.93 & 5.81 \\
\hline & CASPT2 $^{\mathrm{d}}$ & $\cdots$ & 5.37 \\
\hline \multirow[t]{6}{*}{$1{ }^{1} B_{u}\left(V, \pi_{\mathrm{C}=\mathrm{C}^{-}}\right)$} & SAC-CI & 6.36 & 6.03 \\
\hline & Expt. $^{\mathrm{e}}$ & $\ldots$ & 5.73 \\
\hline & Expt. $^{\mathrm{f}}$ & 6.25 & $\ldots$ \\
\hline & CASPT2 $^{d}$ & $\cdots$ & 6.18 \\
\hline & RASSCF $^{c}$ & 6.60 & 6.22 \\
\hline & $\mathrm{MRCI}^{\mathrm{g}}$ & 6.70 & 6.44 \\
\hline $2{ }^{1} B_{u}\left(\pi_{\mathrm{C}=\mathrm{C}^{-}} \rightarrow 3 p_{z}\right)$ & SAC-CI & 7.13 & 6.91 \\
\hline $3{ }^{1} B_{u}\left(\pi_{\mathrm{C}=\mathrm{C}^{-}} \rightarrow 4 p_{z}\right)$ & SAC-CI & 8.21 & 7.96 \\
\hline $1{ }^{1} A_{u}\left(\pi_{\mathrm{C}=\mathrm{C}^{-}} \rightarrow 3 p_{x}\right)$ & SAC-CI & 6.50 & 6.29 \\
\hline $2{ }^{1} A_{u}\left(\pi_{\mathrm{C}=\mathrm{C}^{-}} \rightarrow 3 p_{y}\right)$ & SAC-CI & 6.68 & 6.46 \\
\hline $1{ }^{1} B_{g}\left(\pi_{\mathrm{C}=\mathrm{C}^{-}} \rightarrow 3 s\right)$ & SAC-CI & 6.17 & 5.99 \\
\hline $1{ }^{3} B_{u}^{g}\left(V, \pi_{\mathrm{C}=\mathrm{C}^{-}}\right)$ & SAC-CI & 3.21 & 2.62 \\
\hline $1^{3} A_{g}\left(V, \pi_{\mathrm{C}=\mathrm{C}^{+}}\right)$ & SAC-CI & 5.07 & 4.70 \\
\hline $1{ }^{3} B_{g}^{g}\left(\pi_{\mathrm{C}=\mathrm{C}^{-}} \rightarrow 3 s\right)$ & SAC-CI & 6.12 & 5.94 \\
\hline
\end{tabular}

${ }^{a} \mathrm{SAC}-\mathrm{CI}$ general- $R$ calculation.

${ }^{\mathrm{b}}$ Reference 31.

${ }^{c}$ Reference 29.

${ }^{\mathrm{d}}$ Reference 59.
${ }^{\mathrm{e}}$ Reference 60; Nonplanar conformation.

${ }^{\mathrm{f}}$ Reference 10.

${ }^{\mathrm{g}}$ References 24 and 25. 
lence excited states, $1{ }^{1} B_{u}, 1{ }^{3} B_{u}$, and $1{ }^{3} A_{g}$, respectively. For the $1{ }^{3} B_{u}$ and $1{ }^{3} B_{u}$ states, the $C_{2}-C_{3}$ bond lengths were calculated to shrink by 0.068 and $0.095 \AA$, respectively, while the $\mathrm{C}_{2}-\mathrm{C}_{3}$ bond length of $1{ }^{3} A_{g}$ state elongated by $0.058 \AA$. The SAC-CI geometries of the $1{ }^{1} B_{u}$ state in $C_{2 h}$ structure are in fairly good agreement with those of CASPT2 by Page and Olivucci ${ }^{59}$ and RASSCF (Ref. 59) calculations. Discrepancy was found for only the $\angle \mathrm{CCC}$ in the RASSCF calculation by an amount of $1.9^{\circ}$. The $\mathrm{C}_{1}=\mathrm{C}_{2}$ bond length increases for every excited state due to the reduction in bond order and this is more clearly explained by the SAC-CI density difference as discussed below. The change in $\angle \mathrm{CCC}$ is not unique among the excited states. For $1^{1} B_{u}$ and $1{ }^{3} B_{u}$ states, the CCC bond angle increases slightly and for other cases it decreases as shown in Fig. 1.

Among the triplet excited states for which SAC-CI geometry optimization was performed, the maximum energy lowering due to geometry relaxation is obtained for the $1^{3} B_{u}$ state as $0.59 \mathrm{eV}$. The energy lowering for the $1{ }^{1} B_{u}$ and $1{ }^{3} A_{g}$ states were calculated to be 0.33 and $0.37 \mathrm{eV}$, respectively. Adiabatic energy for the $1{ }^{1} B_{u}$ state in $C_{2 h}$ structure has been examined by several authors. The CASPT2 calculation predicted it as $6.18 \mathrm{eV},{ }^{59}$ and the RASSCF calculation placed it at $6.22 \mathrm{eV} .^{29}$ These values deviate by $\sim 0.2 \mathrm{eV}$ from the present value of $6.03 \mathrm{eV}$, whereas the MRCI gave much higher energy, $6.44 \mathrm{eV} .{ }^{24}$ Experimentally, the adiabatic excitation energy for the $1{ }^{1} B_{u}$ state was measured as $5.73 \mathrm{eV},{ }^{60}$ which is lower than the theoretical values; nonplanar $C_{2}$ structure should be responsible for this energy. The $2{ }^{1} A_{g}$ state showed large relaxation energy, $1.18 \mathrm{eV}$, because of large geometry change such as the increase of the $\mathrm{C}_{1}=\mathrm{C}_{2}\left(\mathrm{C}_{3}=\mathrm{C}_{4}\right)$ bond length by $0.102 \AA$. Adiabatic transition energy for this state obtained in the present calculation is $5.38 \mathrm{eV}$ which is in agreement with the CASSCF value of $5.30 \mathrm{eV} .^{31}$ The CASPT2 calculated values are $5.02 \mathrm{eV}$ (Ref. 31) and $5.37 \mathrm{eV}^{59}$

The SAC-CI geometry optimization was also performed for several Rydberg excited states in $C_{2 h}$ structure; the geometry changes of the Rydberg states were smaller than those of the valence excited states as expected. For the Rydberg states, the elongation of the $\mathrm{C}_{1}=\mathrm{C}_{2}$ bond is around 0.04-0.05 $\AA$, while for the valence excited states it is around $0.1 \AA$ as mentioned above. Similarly, the change in the $\mathrm{C}_{2}-\mathrm{C}_{3}$ bond length is larger for the valence states than the Rydberg states. The electron density distribution is much more affected by the valence excitation than the Rydberg excitation. The $\mathrm{C}-\mathrm{H}$ bonds decrease in length in the excited states. The $\mathrm{HC}_{1} \mathrm{H}$ bond angles increase by $0.6^{\circ}-1.7^{\circ}$, while $\mathrm{C}_{4} \mathrm{C}_{3} \mathrm{H}$ bond angles decrease by $0.1^{\circ}-2.7^{\circ}$ in the excited states.

These changes in the geometry due to excitation can be explained using ESF theory proposed by Nakatsuji. ${ }^{43}$ We discuss here some of the geometry changes in the excited states of butadiene based on the ESF theory. The electron density differences between the ground and excited states are shown in Fig. 2. The electron density in the $\mathrm{C}_{1}=\mathrm{C}_{2}\left(\mathrm{C}_{3}=\mathrm{C}_{4}\right)$ bond region decreases and that in the $\mathrm{C}_{2}-\mathrm{C}_{3}$ bond region increases. More precisely, the electron density in the $\sigma$-bond region increases and the density in the $\pi$-bond region de-

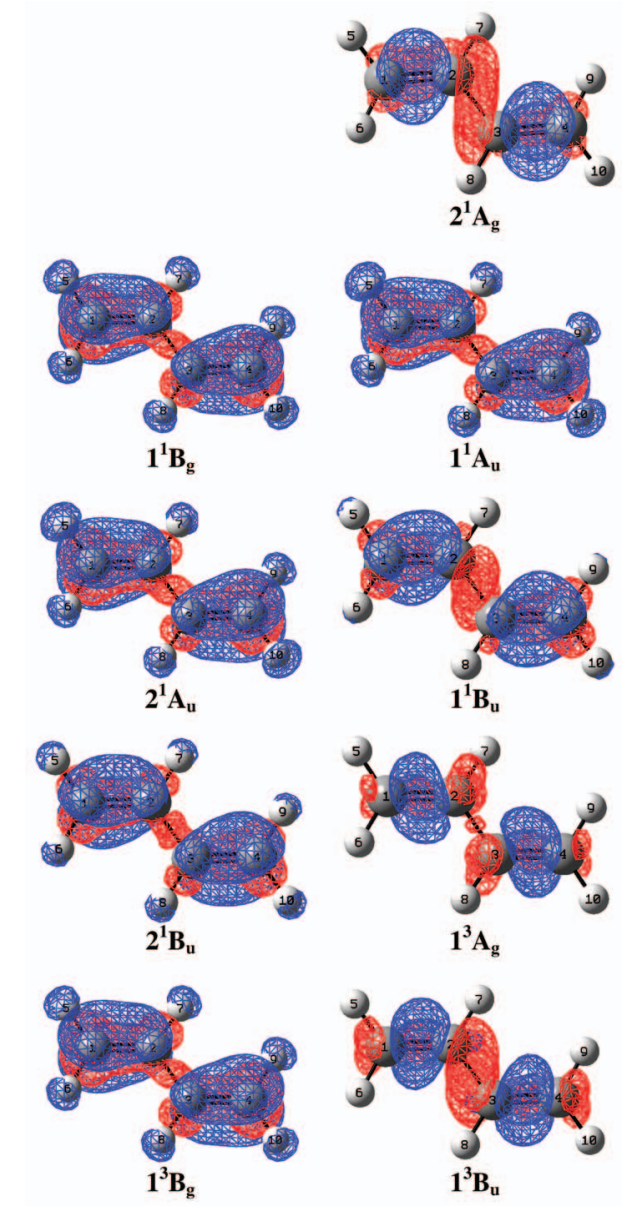

FIG. 2. (Color) SAC-CI electron density difference between the ground and excited states of s-trans 1,3-butadiene. Blue: decrement; red: increment (interval $=0.003$ ).

creases in general. As a consequence, the $\mathrm{C}_{1}=\mathrm{C}_{2}\left(\mathrm{C}_{3}=\mathrm{C}_{4}\right)$ bond increases in length and the $\mathrm{C}_{2}-\mathrm{C}_{3}$ bond decreases. For the excited $1{ }^{1} B_{u}$ and $1{ }^{3} B_{u}$ states comparatively large increment in electron density was obtained which is supported by the change in $\mathrm{C}_{2}-\mathrm{C}_{3}$ bond. Similarly, the $\mathrm{C}_{2}-\mathrm{H}_{7}$ bond decreases in length for the $1{ }^{1} B_{g}$ and $1{ }^{3} B_{g}$ excited states due to an increase of electron density along this bond region. Because of the decrement of electron density in the $\mathrm{C}_{1}=\mathrm{C}_{2}\left(\mathrm{C}_{3}=\mathrm{C}_{4}\right)$ bond region, the exchange (EC) force along this bond decreases, resulting to an increment of the $\angle \mathrm{HC}_{1} \mathrm{H}\left(\angle \mathrm{HC}_{4} \mathrm{H}\right)$ for all the excited states.

\section{ELECTRONIC SPECTRA OF S-TRANS ACROLEIN}

The SAC-CI results of the singlet and triplet excited states of acrolein for vertical transition are summarized in Tables V and VI, respectively. The first ionization potential (IP) obtained from the present calculation was $9.82 \mathrm{eV}$, in comparison with the experimental value of $10.10 \mathrm{eV} .^{50}$ The Hartree-Fock orbital sequence of acrolein is expressed as $\left(12 a^{\prime}\right)^{2}\left(1 a^{\prime \prime}\right)^{2}\left(13 a^{\prime}\right)^{2}\left(2 a^{\prime \prime}\right)^{2}\left(3 a^{\prime \prime}\right)^{0}$ and the absorption of acrolein is due to the $\pi$ electrons and nonbonding oxygen electrons, i.e., excitations from the $2 a^{\prime \prime}$ and $13 a^{\prime}$ MOs, respectively. Therefore, valence excited states of $2 a^{\prime \prime} \rightarrow 3 a^{\prime \prime}\left(A^{\prime}, \pi\right.$ $\left.\rightarrow \pi^{*}\right), 13 a^{\prime} \rightarrow 3 a^{\prime \prime}\left(A^{\prime \prime}, n \rightarrow \pi^{*}\right)$, and Rydberg excited states appear below the ionization threshold. 
TABLE V. Vertical excitation energy $(\Delta E$ in eV), oscillator strength $(f)$, and the electronic part of second moment $\left(\left\langle r^{2}\right\rangle\right.$ in a.u.) for the singlet transitions in s-trans acrolein using $[4 s 2 p 1 d / 2 s]+[2 s 2 p 2 d](n=3)$ basis set.

\begin{tabular}{|c|c|c|c|c|c|c|c|c|}
\hline \multirow[b]{2}{*}{ State/nature } & \multirow{2}{*}{$\begin{array}{c}\text { Expt. }^{\mathrm{a}} \\
\Delta E\end{array}$} & \multicolumn{3}{|c|}{ SAC-CI } & \multicolumn{2}{|c|}{ CASPT2 $^{\mathrm{b}}$} & \multirow{2}{*}{$\frac{\text { MS-CASPT } 2 ~^{\mathrm{b}}}{\Delta E}$} & \multirow[b]{2}{*}{ TDDFT $^{\mathrm{b}}$} \\
\hline & & $\Delta E$ & $F$ & $\left\langle r^{2}\right\rangle$ & $\Delta E$ & $f$ & & \\
\hline$X^{1} A^{\prime}$ & & & & 299.5 & & & & \\
\hline $2{ }^{1} A^{\prime}\left(V, \pi_{\mathrm{C}=\mathrm{C}}\right)$ & 6.42 & 6.92 & 0.3660 & 314.3 & 6.94 & 0.6550 & 6.10 & \\
\hline $3{ }^{1} A^{\prime}\left(V, \pi_{\mathrm{C}=\mathrm{O}}\right)$ & & 8.16 & 0.0948 & 310.5 & 7.43 & 0.0140 & 7.80 & 8.20 \\
\hline $4{ }^{1} A^{\prime}\left(n_{\mathrm{O}} \rightarrow 3 s\right)$ & 7.10 & 7.19 & 0.2355 & 336.6 & 6.75 & 0.0390 & 6.97 & \\
\hline $5{ }^{1} A^{\prime}\left(n_{\mathrm{O}} \rightarrow 3 p_{y}\right)$ & 7.58 & 7.61 & 0.0420 & 357.5 & 7.39 & 0.0110 & 7.55 & \\
\hline $6^{1} A^{\prime}\left(n_{\mathrm{O}} \rightarrow 3 p_{x}\right)$ & 7.77 & 7.83 & 0.0072 & 381.6 & 7.26 & 0.0680 & 7.49 & \\
\hline $7{ }^{1} A^{\prime}\left(\pi_{\mathrm{C}=\mathrm{C}} \rightarrow 3 p_{z}\right)$ & 8.37 & 8.48 & 0.0078 & 354.0 & 8.04 & 0.0470 & 7.91 & \\
\hline $8^{1} A^{\prime}\left(\pi_{\mathrm{C}=\mathrm{C}} \rightarrow 3 d_{x z}\right)$ & 8.49 & 8.58 & 0.0118 & 443.0 & 7.73 & 0.0050 & 8.45 & \\
\hline $9^{1} A^{\prime}\left(n_{\mathrm{O}} \rightarrow 3 d_{x^{2}-y^{2}}\right)$ & & 8.60 & 0.0004 & 425.5 & 8.19 & 0.0001 & 9.18 & \\
\hline $10{ }^{1} A^{\prime}\left(n_{\mathrm{O}} \rightarrow 3 d_{z^{2}}\right)$ & & 8.69 & 0.0024 & 434.8 & 8.27 & 0.0018 & 9.29 & \\
\hline $11^{1} A^{\prime}\left(n_{\mathrm{O}} \rightarrow 3 d_{x y}\right)$ & & 8.80 & 0.0013 & 462.0 & 7.92 & 0.0120 & 8.29 & \\
\hline $12{ }^{1} A^{\prime}\left(\pi_{\mathrm{C}=\mathrm{C}} \rightarrow 3 d_{y z}\right)$ & & 8.84 & 0.0545 & 374.2 & 9.32 & 0.0580 & 9.44 & \\
\hline $1^{1} A^{\prime \prime}\left(V, n_{\mathrm{O}}\right)$ & 3.77 & 3.83 & 0.0001 & 298.7 & 3.63 & 0.0000 & 3.63 & \\
\hline $2{ }^{1} A^{\prime \prime}\left(V, n_{\mathrm{O}}\right)$ & & 7.40 & 0.0000 & 315.7 & 6.26 & 0.0006 & 6.26 & \\
\hline $3{ }^{1} A^{\prime \prime}\left(\pi_{\mathrm{C}=\mathrm{C}} \rightarrow 3 s\right)$ & 7.77 & 7.67 & 0.0546 & 348.6 & 7.76 & 0.0520 & 7.76 & \\
\hline $4{ }^{1} A^{\prime \prime}\left(n_{\mathrm{O}} \rightarrow 3 p_{z}\right)$ & & 7.86 & 0.0013 & 356.8 & 7.74 & 0.0006 & 7.74 & \\
\hline $5{ }^{1} A^{\prime \prime}\left(\pi_{\mathrm{C}=\mathrm{C}} \longrightarrow 3 p_{x}\right)$ & & 8.13 & 0.0003 & 348.8 & 8.27 & 0.0000 & 8.26 & \\
\hline $6{ }^{1} A^{\prime \prime}\left(\pi_{\mathrm{CH}_{2}} \rightarrow 3 p_{z}\right)$ & & 8.55 & 0.0003 & 324.3 & 8.66 & 0.0006 & 8.65 & \\
\hline $7^{1} A^{\prime \prime}\left(\pi_{\mathrm{C}=\mathrm{C}} \rightarrow 3 d_{z^{2}}\right)$ & 8.39 & 8.59 & 0.0022 & 368.7 & 9.48 & 0.0000 & 9.48 & \\
\hline $8{ }^{1} A^{\prime \prime}\left(n_{\mathrm{O}} \rightarrow 3 d_{y z}\right)$ & & 8.62 & 0.0000 & 417.9 & 8.58 & 0.0001 & 8.46 & \\
\hline $9{ }^{1} A^{\prime \prime}\left(n_{\mathrm{O}} \rightarrow 3 d_{x z}\right)$ & & 8.93 & 0.0000 & 416.5 & 8.45 & 0.0000 & 8.58 & \\
\hline $10{ }^{1} A^{\prime \prime}\left(\pi_{\mathrm{C}=\mathrm{C}} \rightarrow 3 d_{x^{2}-y^{2}}\right)$ & & 9.14 & 0.0142 & 372.3 & 9.36 & 0.0007 & 9.36 & \\
\hline $11{ }^{1} A^{\prime \prime}\left(\pi_{\mathrm{C}=\mathrm{C}} \rightarrow 3 d_{x y}\right)$ & & 9.30 & 0.0000 & 416.2 & 9.58 & 0.0090 & 9.58 & \\
\hline
\end{tabular}

${ }^{\mathrm{a}}$ Reference 3 .

${ }^{\mathrm{b}}$ Reference 27.

${ }^{\mathrm{c}} \mathrm{SAC}-\mathrm{CI}$ general- $R$ calculation.

Walsh ${ }^{3}$ reported the absorption spectra of the valence and various Rydberg states for s-trans acrolein. The present results of the vertical transition energies are in good agreement with the values of Walsh. The only other observed transition energy for the lowest $1^{1} A^{\prime \prime}$ state was reported by Becker et al. ${ }^{12}$ We calculated this lowest singlet state at $3.83 \mathrm{eV}$ which shows a fairly good agreement with the observed values, 3.76 (Ref. 3) and $3.75 \mathrm{eV} .^{12}$ This is a valence excitation from $n_{\mathrm{O}}$ orbital with very small oscillator strength of 0.0001. Historically, Dykstra and Schaefer III (Ref. 61) studied the low-lying singlet and triplet states of acrolein by the $\triangle \mathrm{SCF}$ method and calculated lower excitation energies. Very recently, a detailed theoretical investigation on the electronic spectra of acrolein was performed by Aquilante $e \mathrm{al}^{27}$ using the CASPT2 and TDDFT levels of theories. Excitation energies for the lowest $1^{1} A^{\prime \prime}$ state were estimated as 3.63, 3.63, and $3.66 \mathrm{eV}$ by using CASPT2, MS-CASPT2, and TDDFT, respectively. The oscillator strength for this transition was calculated to be 0.00023 by TDDFT.

Lowest $\pi \rightarrow \pi^{*}$ excitation, $2{ }^{1} A^{\prime}$ state, was observed at $6.42 \mathrm{eV}^{3}{ }^{3}$ which is lower than our computed value of $6.92 \mathrm{eV}$. The MS-CASPT (Ref. 27) calculation estimated this state at $6.10 \mathrm{eV}$ whereas CASPT2 and TDDFT (Ref. 27) predicted this state at 6.94 and $6.35 \mathrm{eV}$, respectively. This state corresponds to the $1{ }^{1} B_{u}$ state of butadiene, isoelectronic molecule, calculated at $6.33 \mathrm{eV}$. We obtained this transition dominantly as valence character which is in agreement with the CASPT2 result, ${ }^{27}$ although this state interacts with
TABLE VI. Vertical transition energy $(\Delta E$ in $\mathrm{eV})$ and the electronic part of second moment $\left(\left\langle r^{2}\right\rangle\right.$ in a.u.) for the triplet states in s-trans acrolein using $[4 s 2 p 1 d / 2 s]+[2 s 2 p 2 d](n=3)$ basis set.

\begin{tabular}{|c|c|c|c|c|}
\hline \multirow[b]{2}{*}{ State/nature } & \multicolumn{2}{|c|}{ SAC-CI } & \multirow{2}{*}{$\begin{array}{c}\mathrm{CASPT}^{\mathrm{a}} \\
\Delta E\end{array}$} & \multirow{2}{*}{$\frac{\mathrm{CASSCF}}{\Delta E}$} \\
\hline & $\Delta E$ & $\left\langle r^{2}\right\rangle$ & & \\
\hline $1^{3} A^{\prime}\left(V, \pi_{\mathrm{C}=\mathrm{C}}\right)$ & 3.87 & 300.4 & 3.81 & 3.93 \\
\hline $2{ }^{3} A^{\prime}\left(V, \pi_{\mathrm{C}=\mathrm{O}}\right)$ & 6.21 & 299.9 & & \\
\hline $3^{3} A^{\prime}\left(n_{\mathrm{O}} \rightarrow 3 s\right)$ & 6.70 & 342.1 & & \\
\hline $4^{3} A^{\prime}\left(n_{\mathrm{O}} \rightarrow 3 p_{y}\right)$ & 7.21 & 351.4 & & \\
\hline $5^{3} A^{\prime}\left(n_{\mathrm{O}} \rightarrow 3 p_{x}\right)$ & 7.44 & 373.5 & & \\
\hline $6{ }^{3} A^{\prime}\left(\pi_{\mathrm{C}=\mathrm{C}} \rightarrow 3 p_{z}\right)$ & 8.12 & 392.7 & & \\
\hline $7^{3} A^{\prime} \quad\left(\pi_{\mathrm{C}=\mathrm{C}} \rightarrow 3 d_{y z}\right)$ & 8.14 & 354.4 & & \\
\hline $8^{3} A^{\prime}\left(n_{\mathrm{O}} \rightarrow 3 d_{x^{2}-y^{2}}\right)$ & 8.43 & 476.2 & & \\
\hline $9{ }^{3} A^{\prime} \quad\left(n_{\mathrm{O}} \rightarrow 3 d_{x y}\right)$ & 8.57 & 520.0 & & \\
\hline $10^{3} A^{\prime} \quad\left(\pi_{\mathrm{C}=\mathrm{C}} \rightarrow 3 d_{x z}\right)$ & 8.63 & 342.8 & & \\
\hline $11^{3} A^{\prime}\left(n_{\mathrm{O}} \rightarrow 3 d_{z^{2}}\right)$ & 8.65 & 536.4 & & \\
\hline $1^{3} A^{\prime \prime}\left(V, n_{\mathrm{O}}\right)$ & 3.61 & 298.8 & 3.39 & 3.73 \\
\hline $2^{3} A^{\prime \prime}\left(\pi_{\mathrm{C}=\mathrm{C}} \rightarrow 3 s\right)$ & 7.36 & 335.0 & & \\
\hline $3^{3} A^{\prime \prime}\left(n_{\mathrm{O}} \rightarrow 3 p_{z}\right)$ & 7.65 & 347.6 & & \\
\hline $4{ }^{3} A^{\prime \prime}\left(\pi_{\mathrm{C}=\mathrm{C}} \rightarrow 3 p_{x}\right)$ & 7.90 & 347.4 & & \\
\hline $5^{3} A^{\prime \prime}\left(\pi_{\mathrm{CH}_{2}} \rightarrow 3 p_{z}\right)$ & 8.25 & 343.3 & & \\
\hline $6^{3} A^{\prime \prime}\left(n_{\mathrm{O}} \rightarrow 3 d_{x z}\right)$ & 8.32 & 395.0 & & \\
\hline $7^{3} A^{\prime \prime}\left(\pi_{\mathrm{C}=\mathrm{C}} \rightarrow 3 d_{x y}\right)$ & 8.34 & 375.1 & & \\
\hline $8^{3} A^{\prime \prime}\left(V, \sigma_{\mathrm{C}=\mathrm{O}}\right)$ & 8.53 & 301.5 & & \\
\hline $9^{3} A^{\prime \prime}\left(n_{\mathrm{O}} \rightarrow 3 d_{y z}\right)$ & 8.87 & 483.0 & & \\
\hline $10^{3} A^{\prime \prime}\left(\pi_{\mathrm{C}=\mathrm{C}} \rightarrow 3 d_{z^{2}}\right)$ & 8.90 & 384.0 & & \\
\hline $11^{3} A^{\prime \prime}\left(\pi_{\mathrm{C}=\mathrm{C}} \rightarrow 3 d_{x^{2}}\right)$ & 9.01 & 495.7 & & \\
\hline
\end{tabular}

${ }^{\mathrm{a}}$ Reference 27 
$n_{\mathrm{O}} \rightarrow 3 s$ transition as seen from the second moments and the oscillator strengths. This mixing of Rydberg character was also reported experimentally in some previous studies. ${ }^{15,62}$ Two more valence excited states, $2{ }^{1} A^{\prime \prime}$ and $3{ }^{1} A^{\prime}$ at 6.26 and $7.43 \mathrm{eV}$, respectively, were also reported in the CASPT2 calculation. ${ }^{27}$ We also got transitions of valence character at $7.40 \mathrm{eV}\left(2{ }^{1} A^{\prime \prime}, n_{\mathrm{O}} \rightarrow \pi^{*}\right)$ and $8.16 \mathrm{eV}\left(3{ }^{1} A^{\prime}, n_{\mathrm{C}=\mathrm{O}} \rightarrow \pi^{*}\right)$. The TDDFT, CASPT2, and MS-CASPT2 methods estimated the $3{ }^{1} A^{\prime}$ state at $8.20,7.43$, and $7.80 \mathrm{eV}$, respectively. ${ }^{27}$ For $2{ }^{1} A^{\prime \prime}$ state, the discrepancy between the present and CASPT2 values is quite large; even the higher $R$ operators by general- $R$ calculation did not have effect on the result.

Several Rydberg states are also calculated and the theoretical excitation energies are in excellent agreement with the experimental values; this agreement can be recognized by the comparison with the CASPT2 results. ${ }^{27}$ The excitations from $n_{\mathrm{O}}$ to Rydberg $3 s, 3 p_{y}$, and $3 p_{x}$ were calculated as 7.19, 7.61 , and $7.83 \mathrm{eV}$, respectively, in comparison with the experimental values of $7.10,7.58$, and $7.77 \mathrm{eV}$, respectively. ${ }^{3}$ The transitions from $\pi$ orbital were predicted in higher energy region, reflecting the binding energies as 8.48 and $7.67 \mathrm{eV}$ for $\pi \rightarrow 3 p_{z}$ and $\pi \rightarrow 3 s$ states, respectively, and the corresponding experimental values are 8.51 and $7.75 \mathrm{eV}$, respectively. ${ }^{3}$ We also calculated the transitions to Rydberg $3 d$ states and the oscillator strength of these transitions are reasonably small as seen in Table V. Comparing with the assignments by the CASPT2 calculation, the molecular axis is different between the present and CASPT2 works, otherwise the present assignment almost agree with the CASPT2 assignments. ${ }^{27}$ However, for some Rydberg states, the calculated excitation energies are very different from the CASPT2 values. It was noted that the MS-CASPT2 is reliable for these Rydberg states. ${ }^{27}$ We also compared the MS-CASPT2 (Ref. 27) values in Table $\mathrm{V}$ and found better agreement for these Rydberg excitations. However, still a large difference, $\sim 0.6 \mathrm{eV}$, exists for some Rydberg states, e.g., ${ }^{1} A^{\prime}\left(n_{\mathrm{O}}\right.$ $\left.\rightarrow 3 d_{z^{2}}\right)$ and ${ }^{1} A^{\prime}\left(n_{\mathrm{O}} \rightarrow 3 d_{x y}\right)$. The assignments for a few higher Rydberg states are also different. We believe that the SAC-CI results for Rydberg states are reliable based on many previous calculations. ${ }^{63}$

For the triplet excited states, the lowest triplet $1{ }^{3} A^{\prime \prime}\left(n_{\mathrm{O}}\right.$ $\left.\rightarrow \pi^{*}\right)$ state was calculated to be $3.61 \mathrm{eV}$. The CASSCF and CASPT2 calculations reported values as 3.73 and $3.39 \mathrm{eV}$, respectively. ${ }^{27}$ We estimated the second triplet state, $1^{3} A^{\prime}\left(\pi_{\mathrm{C}=\mathrm{C}} \rightarrow \pi^{*}\right)$, at $3.87 \mathrm{eV}$, which is in good agreement with the previous theoretical results, CASSCF $(3.93 \mathrm{eV})$ and CASPT2 $(3.81 \mathrm{eV}) .{ }^{27}$ We also calculated higher triplet excited states of Rydberg transitions, which are $0.2-0.5 \mathrm{eV}$ lower than the corresponding singlet excited states. Unfortunately, there are no experimental and theoretical information for the higher triplet states for this molecule.

\section{GROUND- AND EXCITED-STATE GEOMETRIES OF S-TRANS ACROLEIN}

Optimized geometries for the ground state and several excited states of s-trans acrolein are displayed in Fig. 3 and the comparison of geometries has been done in Table VII. The adiabatic transition energies are shown in Table VIII.
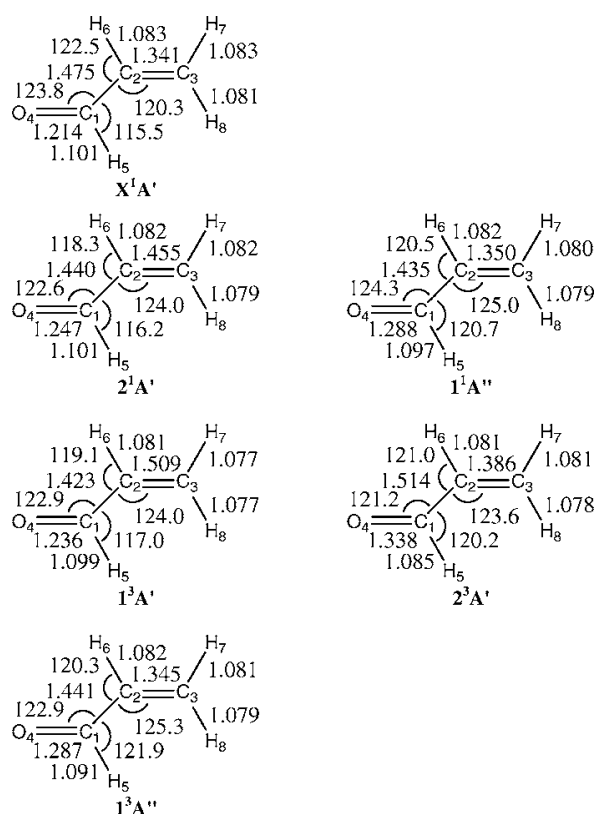

FIG. 3. Geometries for the ground and excited states of s-trans acrolein optimized by the SAC-CI method. Bond lengths and angles are in $\AA$ and degree, respectively.

The ground state geometry agrees very well with the experimental geometry due to Blom and Bauder. ${ }^{62}$ The $\mathrm{C}_{1}-\mathrm{C}_{2}$, $\mathrm{C}_{2}=\mathrm{C}_{3}$, and $\mathrm{C}_{1}=\mathrm{O}$ bond lengths of the ground state agree within $0.005,0.004$, and $0.005 \AA$, respectively, with the corresponding experimental values, while $\angle \mathrm{C}_{1} \mathrm{C}_{2} \mathrm{C}_{3}$ and $\angle \mathrm{C}_{2} \mathrm{C}_{1} \mathrm{O}$ are deviated by $0.5^{\circ}$ and $0.4^{\circ}$, respectively. The present results for the ground state show good agreement with the CASPT2. ${ }^{27}$

The excited-state geometries were examined by the CASPT2 (Ref. 27) method for three low-lying singlet and triplet states; $1{ }^{1} A^{\prime \prime}$ and $1{ }^{3} A^{\prime \prime}$ states were found to be planar and $1^{3} A^{\prime}$ state nonplanar. The SAC-CI geometry optimization was performed for five excited states of valence character, namely, $1^{1} A^{\prime \prime}, 2{ }^{1} A^{\prime}, 1{ }^{3} A^{\prime}, 2{ }^{3} A^{\prime}$, and $1^{3} A^{\prime \prime}$ states in the planar structure. Among these states, the $1^{3} A^{\prime}$ and $2^{3} A^{\prime}$ states, both of which correspond to $\pi \rightarrow \pi^{*}$ transition, were calculated to be lowered by 0.41 and $0.64 \mathrm{eV}$, respectively, due to geometry relaxation. In the case of $1^{1} A^{\prime \prime}$ state we adopted the localized molecular orbital (LMO) method to compute the adiabatic transition energy. Using LMO we obtained improvement of the transition energy, $3.38 \mathrm{eV}$, which is deviated by $0.33 \mathrm{eV}$ from the corresponding experimental result of $3.05 \mathrm{eV} .{ }^{64}$ For the other states, $2{ }^{1} A^{\prime}$, and $1{ }^{3} A^{\prime \prime}$ states, the energy stabilizations due to geometry relaxation were quite small $0.03-0.1 \mathrm{eV}$. We got a value of $3.42 \mathrm{eV}$ for the $1^{3} A^{\prime \prime}$ state, corresponding available experimental value is $3.01 \mathrm{eV}^{14}$ In the $\triangle \mathrm{SCF}$ calculation, ${ }^{61}$ the energy obtained lowering for $1^{3} A^{\prime}$ and $1^{3} A^{\prime \prime}$ states were as large as 1.11 and $0.68 \mathrm{eV}$, respectively.

For the first singlet excited $1{ }^{1} A^{\prime \prime}$ state, good agreement was obtained between the experimental and computed geometrics. In this case, we got the same values as the experiment for the $\mathrm{C}_{2}=\mathrm{C}_{3}$ bond length and $\angle \mathrm{C}_{1} \mathrm{C}_{2} \mathrm{C}_{3}$. ${ }^{64}$ The $\mathrm{C}_{1}-\mathrm{C}_{2}$ and $\mathrm{C}_{1}=\mathrm{O}$ bond lengths are deviated by 0.025 and $0.032 \AA$, respectively, from the experimental values. ${ }^{64}$ For all 
TABLE VII. Comparison of optimized geometries of ground and four excited states for s-trans acrolein using $[4 s 2 p 1 d / 2 s]+[2 s 2 p](n=3)$ basis set. The bond length and bond angle are in $\AA$ and degree, respectively.

\begin{tabular}{llccccc}
\hline \hline State/nature & Method & $\mathrm{C}_{1}-\mathrm{C}_{2}$ & $\mathrm{C}_{2}=\mathrm{C}_{3}$ & $\mathrm{C}_{1}=\mathrm{O}$ & $\angle \mathrm{C}_{1} \mathrm{C}_{2} \mathrm{C}_{3}$ & $\angle \mathrm{C}_{2} \mathrm{C}_{1} \mathrm{O}$ \\
\hline$X^{1} A^{\prime}$ & SAC-CI & 1.475 & 1.341 & 1.214 & 120.3 & 123.8 \\
& Expt. $^{\mathrm{a}}$ & 1.470 & 1.345 & 1.219 & 119.8 & 123.4 \\
& CASPT2 $^{\mathrm{b}}$ & 1.467 & 1.344 & 1.222 & 120.5 & 124.2 \\
& PBE0 $^{\mathrm{b}}$ & 1.471 & 1.332 & 1.204 & 120.7 & 124.4 \\
$1^{1} A^{\prime \prime}\left(V, n_{\mathrm{O}}\right)$ & SAC-CI & 1.435 & 1.350 & 1.288 & 125.0 & 124.3 \\
& Expt. $^{\mathrm{c}}$ & 1.460 & 1.350 & 1.320 & 125.0 & 125.0 \\
& CASPT2 $^{\mathrm{b}}$ & 1.381 & 1.393 & 1.342 & 123.0 & 120.0 \\
$1^{3} \mathrm{~A}^{\prime}\left(V, \pi_{\mathrm{C}=\mathrm{C}}\right)$ & SAC-CI $^{3}{ }^{3} \mathrm{~A}^{\prime \prime}\left(V, n_{\mathrm{O}}\right)$ & 1.423 & 1.509 & 1.236 & 124.0 & 122.9 \\
& CASPT2 $^{\mathrm{b}}$ & 1.437 & 1.457 & 1.231 & $\cdots$ & $\cdots$ \\
& SAC-C1 & 1.441 & 1.345 & 1.287 & 125.3 & 122.9 \\
\hline
\end{tabular}

${ }^{\mathrm{a}}$ Reference 62.

${ }^{\mathrm{b}}$ Reference 27.

${ }^{\mathrm{c}}$ Reference 64 .

the excited states reported here, the $\mathrm{C}_{1}-\mathrm{C}_{2}$ bond was predicted to be contracted relative to the ground state whereas the change in $\mathrm{C}_{1}=\mathrm{O}$ bond was negligible. For the $2{ }^{1} A^{\prime}$ and $1{ }^{3} A^{\prime}$ states the $C_{2}=C_{3}$ bond increases by 0.114 and $0.168 \AA$, respectively. This is a clear evidence of $\pi_{\mathrm{C}=\mathrm{C}}$ $\rightarrow \pi^{*}$ transition. A noticeable change, $3.7^{\circ}$, of the $\angle \mathrm{C}_{1} \mathrm{C}_{2} \mathrm{C}_{3}$ was also predicted for these states, whereas the $\angle \mathrm{C}_{2} \mathrm{C}_{1} \mathrm{O}$ is changed by $1.2^{\circ}$ and $0.9^{\circ}$, respectively. Similarly, $1{ }^{1} A^{\prime \prime}$ and $1^{3} A^{\prime \prime}$ states correspond to $n_{\mathrm{O}} \rightarrow \pi^{*}$ transition where an elongation of $\mathrm{C}_{1}=\mathrm{O}$ bond length by $0.074 \AA$ and an increment of the $\angle \mathrm{C}_{2} \mathrm{C}_{1} \mathrm{C}_{3}$ by $4.7^{\circ}$ and $5^{\circ}$, respectively, were obtained. Most of the SCF optimized geometries of Dykstra and Schaefer III (Ref. 61) for excited states agree with the present data. However, there are deviations in some cases. For example, in the excited $1{ }^{3} A^{\prime}$ state, the $\mathrm{C}_{1}=\mathrm{O}$ bond length is deviated by $0.16 \AA$. The $\mathrm{C}-\mathrm{H}$ bonds decrease in length in the excited states. Large decrement of the $\angle \mathrm{C}_{1} \mathrm{C}_{2} \mathrm{H}$ was obtained, $1.5^{\circ}-4.2^{\circ}$, in particular for the $2{ }^{1} A^{\prime}$ excited state, $4.2^{\circ}$. On the other hand, the $\mathrm{C}_{2} \mathrm{C}_{1} \mathrm{H}$ bond angles opened around $1^{\circ}-6^{\circ}$; maximum change, $6^{\circ}$, was obtained for the excited $1^{3} A^{\prime \prime}$ state.

For acrolein, we also calculated the electron density difference and applied the ESF theory to interpret the geometrical changes. The SAC-CI electronic density differences are displayed in Fig. 4. For the $2{ }^{1} A^{\prime}$ and $1{ }^{3} A^{\prime}$ states, the electron density decreases in the $\pi$ region of $\mathrm{C}_{2}=\mathrm{C}_{3}$ bond.

TABLE VIII. Adiabatic excitation energy (in eV) of s-trans acrolein using $[4 s 2 p 1 d / 2 s]+[2 s 2 p](n=3)$ basis set.

\begin{tabular}{|c|c|c|c|c|}
\hline \multirow[b]{2}{*}{ State/nature } & \multirow{2}{*}{$\begin{array}{l}\text { Vertical } \\
\text { SAC-CI }\end{array}$} & \multicolumn{3}{|c|}{ Adiabatic } \\
\hline & & Expt. & SAC-CI & $\mathrm{CASPT}^{\mathrm{a}}$ \\
\hline $1{ }^{1} A^{\prime \prime}\left(V, n_{\mathrm{O}}\right)$ & 3.84 & $3.05^{\mathrm{b}}$ & 3.38 & 3.12 \\
\hline $2{ }^{1} A^{\prime}\left(V, \pi_{\mathrm{C}=\mathrm{C}}\right)$ & 6.95 & & 6.92 & \\
\hline $1{ }^{3} A^{\prime}\left(V, \pi_{\mathrm{C}=\mathrm{C}}\right)$ & 3.73 & & 3.32 & 1.46 \\
\hline $2^{3} A^{\prime}\left(V, \pi_{\mathrm{C}=\mathrm{O}}\right)$ & 6.04 & & 5.40 & \\
\hline $1^{3} A^{\prime \prime}\left(V, n_{\mathrm{O}}\right)$ & 3.53 & $3.01^{\mathrm{c}}$ & 3.42 & 2.92 \\
\hline
\end{tabular}

${ }^{\mathrm{a}}$ Reference 27.

${ }^{\mathrm{b}}$ Reference 64.

${ }^{c}$ Reference 14; 0-0 transition energies.
Hence, the change of EC force occurs and the $\mathrm{C}_{2}=\mathrm{C}_{3}$ bond length increases. The opposite effect was obtained for the $\mathrm{C}_{1}-\mathrm{C}_{2}$ bond due to the increase of electron density in this $\sigma$-bond region. The $\angle \mathrm{C}_{1} \mathrm{C}_{2} \mathrm{C}_{3}$ increases also due to the change in the EC force. On the other hand, the $\angle \mathrm{C}_{2} \mathrm{C}_{1} \mathrm{O}$ decreases slightly due to the change in atomic dipole (AD) force as the electron density of the lone pair of oxygen increases. The $\mathrm{C}_{1}=\mathrm{O}$ bond increases whereas the $\mathrm{C}_{1}-\mathrm{C}_{2}$ bond decreases as the changes in the electron density and consequently the changes in the EC force in these bond regions are opposite.

\section{ELECTRONIC SPECTRA OF S-TRANS GLYOXAL}

Vertical transition energies below the ionization threshold of s-trans glyoxal are summarized in Tables IX and X for singlet and triplet states, respectively. The first IP was calculated to be $10.49 \mathrm{eV}$, in agreement with the experimental value of $10.60 \mathrm{eV} .^{50}$ Glyoxal has delocalized $\pi$ electrons and

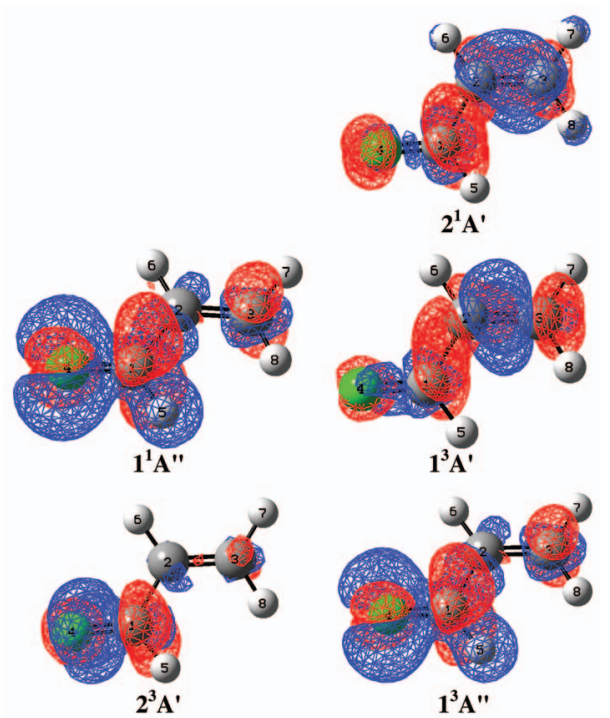

FIG. 4. (Color) SAC-CI electron density difference between the ground and excited states of s-trans acrolein. Blue: decrement; red: increment (interval $=0.003$ ) 
TABLE IX. Vertical excitation energy ( $\Delta E$ in $\mathrm{eV})$, oscillator strength $(f)$, and the electronic part of second moment $\left(\left\langle r^{2}\right\rangle\right.$ in a.u. $)$ for the singlet transitions in s-trans glyoxal using $[4 s 2 p 1 d / 2 s]+[2 s 2 p 2 d](n=3)$ $+[2 s 2 p](n=4)$ basis set.

\begin{tabular}{|c|c|c|c|c|c|c|}
\hline \multirow[b]{2}{*}{ State/nature } & \multirow{2}{*}{$\begin{array}{l}\text { Expt. } \\
\Delta E\end{array}$} & \multicolumn{3}{|c|}{ SAC-CI } & \multirow{2}{*}{$\begin{array}{l}\mathrm{SAC}^{\mathrm{SAC}} \mathrm{a}^{\mathrm{a}} \\
\text { (previous) }\end{array}$} & \multirow[b]{2}{*}{$\mathrm{CASSCF}^{\mathrm{b}}$} \\
\hline & & $\Delta E$ & $f$ & $\left\langle r^{2}\right\rangle$ & & \\
\hline$X^{1} A_{g}$ & & 0.00 & & 268.8 & & \\
\hline $2{ }^{1} A_{g}\left(V, n_{\mathrm{O}^{+2}}\right)^{\mathrm{c}}$ & & 5.66 & 0.0000 & 269.4 & & \\
\hline $3{ }^{1} A_{g}^{g}\left(n_{\mathrm{O}^{+}} \rightarrow 3 s\right)^{\mathrm{c}}$ & & 6.55 & 0.0000 & 343.9 & & \\
\hline $4{ }^{1} A_{g}^{\circ}\left(n_{\mathrm{O}^{+}} \rightarrow 3 d_{z^{2}}\right)$ & & 8.83 & 0.0000 & 358.0 & & \\
\hline $5{ }^{1} A_{g}\left(n_{\mathrm{O}^{+}} \rightarrow 3 d_{x^{2}-y^{2}}\right)$ & & 9.03 & 0.0000 & 400.2 & & \\
\hline $6{ }^{1} A_{g}\left(n_{\mathrm{O}^{+}} \rightarrow 4 s\right)$ & & 9.07 & 0.0000 & 415.1 & & \\
\hline $7{ }^{1} A_{g}^{\circ}\left(n_{\mathrm{O}^{+}} \rightarrow 3 d_{x y}\right)$ & & 9.24 & 0.0000 & 463.0 & & \\
\hline $1{ }^{1} B_{g}^{8}\left(V, n_{\mathrm{O}^{-}}\right)$ & $4.2,{ }^{\mathrm{d}} 4.46,{ }^{\mathrm{e}} 4.63^{\mathrm{f}}$ & 4.68 & 0.0000 & 267.3 & 4.97 & 4.36 \\
\hline $2{ }^{1} B_{g}^{g}\left(V, n_{\mathrm{O}^{+}}\right)$ & $7.10,^{\mathrm{g}} 7.45^{\mathrm{h}}$ & 7.54 & 0.0000 & 272.7 & & \\
\hline $3{ }^{1} B_{g}\left(n_{\mathrm{O}^{+}} \rightarrow 3 d_{x z}\right)$ & & 9.03 & 0.0000 & 388.7 & & \\
\hline $4{ }^{1} B_{g}\left(n_{\mathrm{O}^{+}} \rightarrow 3 d_{y z}\right)$ & & 9.16 & 0.0000 & 416.0 & & \\
\hline $5{ }^{1} B_{g}\left(\sigma_{\mathrm{CO}^{+}} \rightarrow 3 p_{z}\right)$ & & 9.77 & 0.0000 & 408.5 & & \\
\hline $1^{1} A_{u}^{s}\left(V, n_{\mathrm{O}^{-}}\right)$ & $2.8^{\mathrm{d}}$ & 3.10 & 0.0002 & 267.2 & 3.53 & 3.21 \\
\hline $2{ }^{1} A_{u}\left(n_{\mathrm{O}^{+}} \rightarrow 3 p_{z}\right)$ & & 8.11 & 0.0026 & 325.4 & & \\
\hline $3{ }^{1} A_{u}^{u}\left(V, \sigma_{\mathrm{CO}^{-}}\right)$ & & 8.83 & 0.0004 & 270.5 & & \\
\hline $4{ }^{1} A_{u}\left(V, \sigma_{\mathrm{CO}^{-}}\right)$ & & 9.24 & 0.0013 & 284.1 & & \\
\hline $5{ }^{1} A_{u}\left(n_{\mathrm{O}^{+}} \rightarrow 4 p_{z}\right)$ & & 9.39 & 0.0020 & 516.3 & & \\
\hline $1{ }^{1} B_{u}\left(n_{\mathrm{O}^{+}} \rightarrow 3 p_{x}\right)$ & $7.9^{\mathrm{d}}$ & 7.83 & 0.0889 & 316.1 & 9.78 & \\
\hline $2{ }^{1} B_{u}\left(n_{\mathrm{O}^{+}} \rightarrow 3 p_{y}\right)$ & & 8.17 & 0.0362 & 326.8 & & \\
\hline $3{ }^{1} B_{u}\left(V, \pi_{\mathrm{C}=\mathrm{O}^{-}}\right)$ & & 8.86 & 0.4311 & 271.7 & & \\
\hline $4{ }^{1} B_{u}\left(n_{\mathrm{O}^{+}} \rightarrow 4 p_{x}\right)$ & & 9.28 & 0.0253 & 511.6 & & \\
\hline $5{ }^{1} B_{u}\left(n_{\mathrm{O}^{+}} \rightarrow 4 p_{y}\right)$ & & 9.34 & 0.0247 & 508.2 & & \\
\hline $\begin{array}{l}{ }^{\mathrm{a}} \text { Reference } 19 . \\
{ }^{\mathrm{b}} \text { Reference } 36 . \\
{ }^{\mathrm{c}} \text { SAC-CI general- } R \text { ca } \\
{ }^{\mathrm{d}} \text { Reference } 7 .\end{array}$ & tion. & & $\begin{array}{l}\text { Referenc } \\
\text { Referenc } \\
\text { Referenc } \\
\text { Referenc }\end{array}$ & and 70 & & \\
\hline
\end{tabular}

lone-pair electrons on the oxygen atom. The lone pair orbitals constitute $n^{+}$and $n^{-}$orbitals. The valence MOs are $n^{+}, n^{-}$, $\pi_{\mathrm{C}=\mathrm{O}^{-}}$, and $\pi_{\mathrm{C}=\mathrm{O}^{+}}$in the order of increasing IP experimentally proposed by Turner, ${ }^{37}$ which is in agreement with the present SAC-CI results. The previous systematic SAC-CI study ${ }^{65}$ on the valence shell of $4 \pi$-conjugated molecules also gave the same ordering for these states. Therefore, the excitations corresponding to $\pi \rightarrow \pi^{*}$ transition are relatively higher in energy than those of $n \rightarrow \pi^{*}$; the order of valence shell is important for the correct assignments of the excited states.

The first singlet and triplet $A_{u}\left(n \rightarrow \pi^{*}\right)$ states were experimentally observed and well established. We have calculated these states at 3.10 and $2.63 \mathrm{eV}$ which deviate by 0.30 and $0.13 \mathrm{eV}$, respectively, from the corresponding observed values, 2.8 and $2.5 \mathrm{eV} ;^{7}$ the agreement is better than the previous SAC-CI calculation. ${ }^{19}$ The valence $1{ }^{1} B_{g}$ state was calculated at $4.68 \mathrm{eV}$ in the present calculation and was characterized as the excitation from the $n_{\mathrm{O}^{+}}$orbital. This result is corroborated by some experimental works such as the electron-impact spectroscopy of Verhaart and Brongersma; ${ }^{7}$ the experimental values were reported as $4.2,{ }^{7} 4.46,{ }^{66}$ and $4.63 \mathrm{eV}$ (Ref. 67) for this state. This state was also reported by other theoretical calculations, ${ }^{18}$ however, the estimated values range widely as $3.47,{ }^{18} 3.96,{ }^{68} 4.97,{ }^{19}$ and $4.36 \mathrm{eV}^{36}$

In higher energy region, we obtained the Rydberg transition $1{ }^{1} B_{u}\left(n^{+} \rightarrow 3 p_{x}\right)$ at $7.83 \mathrm{eV}$ which agrees with the observed state at $7.9 \mathrm{eV}$ by Verhaart and Brongersma, ${ }^{7}$ but,
TABLE $X$. Vertical excitation energy $(\Delta E$ in $\mathrm{eV})$ and the electronic part of second moment $\left(\left\langle r^{2}\right\rangle\right.$ in a.u. $)$ for the triplet transitions in s-trans glyoxal using $[4 s 2 p 1 d / 2 s]+[2 s 2 p 2 d](n=3)+[2 s 2 p](n=4)$ basis set.

\begin{tabular}{|c|c|c|c|c|c|c|}
\hline \multirow[b]{2}{*}{ State/nature } & \multirow{2}{*}{$\begin{array}{c}\text { Expt. }^{\mathrm{a}} \\
\Delta E\end{array}$} & \multicolumn{2}{|c|}{ SAC-CI } & \multirow{2}{*}{$\begin{array}{l}\mathrm{SAC}^{-\mathrm{CI}^{\mathrm{b}}} \\
\text { (previous) }\end{array}$} & \multirow[b]{2}{*}{$\mathrm{CI}^{\mathrm{c}}$} & \multirow[b]{2}{*}{ CASSCF $^{\mathrm{d}}$} \\
\hline & & $\Delta E$ & $\left\langle r^{2}\right\rangle$ & & & \\
\hline $1{ }^{3} A_{g}\left(V, \pi_{\mathrm{C}=\mathrm{O}^{+}}\right)$ & & 6.31 & 268.1 & & & \\
\hline $2{ }^{3} A_{g}\left(n_{\mathrm{O}^{+}} \rightarrow 3 s\right)$ & & 7.39 & 308.6 & & & \\
\hline $3{ }^{3} A_{g}\left(n_{\mathrm{O}^{+}} \rightarrow 3 d_{z^{2}}\right)$ & & 8.74 & 339.2 & & & \\
\hline $4{ }^{3} A_{g}^{\circ}\left(n_{\mathrm{O}^{+}} \rightarrow 3 d_{x^{2}-y^{2}}\right)$ & & 8.98 & 382.8 & & & \\
\hline $5^{3} A_{g}^{s}\left(n_{\mathrm{O}^{+}} \rightarrow 4 s\right)$ & & 9.04 & 421.7 & & & \\
\hline $6^{3} A_{g}\left(n_{\mathrm{O}^{+}} \rightarrow 3 d_{x y}\right)$ & & 9.23 & 451.1 & & & \\
\hline $1{ }^{3} B_{g}^{s}\left(V, n_{\mathrm{O}^{-}}\right)$ & 3.8 & 4.12 & 267.2 & 4.13 & 4.58 & 3.64 \\
\hline $2{ }^{3} B_{g}^{\circ}\left(V, n_{\mathrm{O}^{+}}\right)$ & & 7.42 & 271.8 & & & \\
\hline $3{ }^{3} B_{g}\left(V, \sigma_{\mathrm{CO}^{+}}\right)$ & & 8.85 & 275.5 & & & \\
\hline $4{ }^{3} B_{g}^{\circ}\left(n_{\mathrm{O}^{+}} \rightarrow 3 d_{x z}\right)$ & & 9.03 & 381.3 & & & \\
\hline $5^{3} B_{g}\left(n_{\mathrm{O}^{+}} \rightarrow 3 d_{x z}\right)$ & & 9.20 & 403.7 & & & \\
\hline $1{ }^{3} A_{u}\left(V, n_{\mathrm{O}^{+}}\right)$ & 2.5 & 2.63 & 267.1 & 2.9 & 2.86 & 2.53 \\
\hline $2{ }^{3} A_{u}\left(V, \sigma_{\mathrm{CO}^{-}}\right)$ & & 8.05 & 267.8 & & & \\
\hline $3{ }^{3} A_{u}\left(n_{\mathrm{O}^{+}} \rightarrow 3 p_{z}\right)$ & & 8.09 & 324.4 & & & \\
\hline $4{ }^{3} A_{u}\left(V, n_{\mathrm{O}^{-}}\right)$ & & 8.91 & 270.1 & & & \\
\hline $5^{3} A_{u}\left(n_{\mathrm{O}^{+}} \rightarrow 4 p_{z}\right)$ & & 9.37 & 525.6 & & & \\
\hline $1{ }^{3} B_{u}\left(V, \pi_{\mathrm{C}=\mathrm{O}^{-}}\right)$ & 5.2 & 5.35 & 267.6 & 5.43 & 5.11 & \\
\hline $2{ }^{3} B_{u}\left(n_{\mathrm{O}^{+}} \rightarrow 3 p_{x}\right)$ & & 7.65 & 307.5 & & & \\
\hline $3{ }^{3} B_{u}\left(n_{\mathrm{O}^{+}} \rightarrow 3 p_{y}\right)$ & & 8.06 & 319.4 & & & \\
\hline $4{ }^{3} B_{u}\left(n_{\mathrm{O}^{+}} \rightarrow 4 p_{x}\right)$ & & 9.21 & 488.3 & & & \\
\hline $5^{3} B_{u}\left(n_{\mathrm{O}^{+}} \rightarrow 4 p_{y}\right)$ & & 9.29 & 501.4 & & & \\
\hline
\end{tabular}

${ }^{\mathrm{a}}$ Reference 7.

${ }^{\mathrm{b}}$ Reference 19.
${ }^{\mathrm{c}}$ Reference 20 .

${ }^{\mathrm{d}}$ Reference 36. 
TABLE XI. Comparison of optimized geometries for the ground state of s-trans glyoxal using $[4 s 2 p 1 d / 2 s]+[2 s 2 p](n=3)$ basis set. Bond length and angle are in $\AA$ and degree, respectively.

\begin{tabular}{llcccc}
\hline \hline State/nature & Method & $\mathrm{C}-\mathrm{C}$ & $\mathrm{C}=\mathrm{O}$ & $\angle \mathrm{CCO}$ & $\angle \mathrm{CCH}$ \\
\hline$X^{1} A_{g}$ & SAC-CI & 1.527 & 1.208 & 121.1 & 114.9 \\
& Expt. $^{\mathrm{a}}$ & 1.530 & 1.205 & 120.9 & 113.7 \\
& Expt. $^{\mathrm{b}}$ & 1.527 & 1.202 & 121.2 & 115.5 \\
& CCSD $^{\mathrm{c}}$ & 1.524 & 1.203 & 121.2 & 115.4 \\
$1^{1} A_{u}\left(V, n_{\mathrm{O}^{+}}\right)$ & SAC-CI $^{\mathrm{a}}$ & 1.500 & 1.227 & 123.8 & 113.6 \\
& Expt. $^{\mathrm{a}}$ & 1.481 & 1.242 & 123.6 & 112.3 \\
& Expt. $^{\mathrm{b}}$ & 1.460 & 1.252 & 123.7 & 114.0 \\
& EOMEE-CCSD $^{\mathrm{c}}$ & 1.496 & 1.229 & 123.5 & 114.0 \\
\hline \hline
\end{tabular}

${ }^{\mathrm{a}}$ Reference 74 .

${ }^{\mathrm{b}}$ Reference 75.

${ }^{\mathrm{c}}$ Reference 76.

their assignment was different as $\pi \rightarrow \pi^{*}$ transition. Robin ${ }^{69}$ assigned a diffuse band at $7.75 \mathrm{eV}$ in Walsh's ${ }^{1,70}$ optical spectrum to $n^{+} \rightarrow 3 p$ Rydberg state. We also performed the general- $R$ calculations for the lowest two states of $A_{g}$ symmetry. We obtained the valence $2{ }^{1} A_{g}$ state at a value of $5.66 \mathrm{eV}$ and $3{ }^{1} A_{g}\left(n^{+} \longrightarrow 3 s\right)$ Rydberg transition at a value of $6.55 \mathrm{eV}$. Leclerq et al. ${ }^{18}$ reported a low value of $4.95 \mathrm{eV}$ for the $2{ }^{1} B_{g}$ state. Robin ${ }^{69}$ assigned the $n^{+} \rightarrow 3 s$ Rydberg state at $7.45 \mathrm{eV}$. But we assigned this peak as the valence $2{ }^{1} B_{g}$ state which we obtained at $7.54 \mathrm{eV}$.

The low-lying triplet states were predicted in the order of ${ }^{3} A_{u}<{ }^{3} B_{u}<{ }^{3} B_{g}$ in SCF (Ref. 71) and the previous SAC-CI calculations, ${ }^{19}$ whereas in the present SAC-CI and previous CI (Ref. 20) studies, the ordering of the levels was calculated to be ${ }^{3} A_{u}<{ }^{3} B_{g}<{ }^{3} B_{u}$. We obtained a very strong $\pi \rightarrow \pi^{*}$ valence transition $3{ }^{1} B_{u}$ with the oscillator strength of 0.431 , however, there is no experimental evidence for this transition, since this state lies in high energy region just below the ionization threshold.

\section{GROUND-AND EXCITED-STATE GEOMETRIES OF S-TRANS GLYOXAL}

Comparison of the optimized geometries with the available experimental and other theoretical values has been made in Table XI. Optimized geometries and adiabatic excitation energies are displayed in Fig. 5 and Table XII, respectively. Herzberg ${ }^{72}$ reported that $S_{0}, S_{1}$, and $T_{1}$ states of trans-glyoxal have $C_{2 h}$ planar structure. This planar structure for the $S_{0}$ and $S_{1}$ states of s-trans glyoxal was also confirmed by other experimental works. ${ }^{73,74}$ Again, the SAC-CI ground state geometry agrees very well with the experimental observations of Paldus and Ramasay ${ }^{74}$ and Briss et al. ${ }^{75}$ Deviations of the $\mathrm{C}-\mathrm{C}$ and $\mathrm{C}=\mathrm{O}$ bond lengths from experimental values are 0.003 and $0.008 \AA$, respectively. ${ }^{75} \angle \mathrm{CCO}$ and $\angle \mathrm{CCH}$ also deviate very less from the experimental values, within $0.1^{\circ}$ and $0.6^{\circ}$, respectively. ${ }^{75}$ The CCSD calculation of Stanton and Gauss ${ }^{76}$ for the ground state of glyoxal using TZ2P basis set also gave the same results.

Experimental geometry due to Paldus and Ramasay ${ }^{74}$ for the ${ }^{1} A_{u}$ excited state agrees well with our computed geometries. In the excited states, the $\mathrm{C}=\mathrm{O}$ bond is elongated and the $\mathrm{CC}$ bond decreases in length. The increments of the
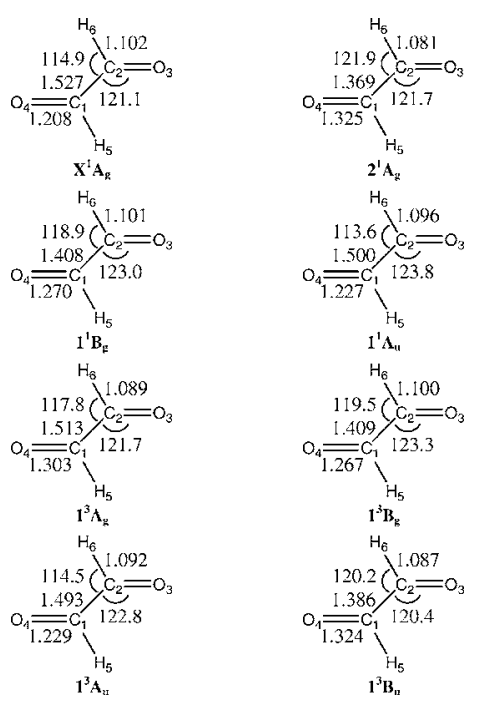

FIG. 5. Geometries for the ground and excited states of s-trans glyoxal optimized by the SAC-CI method. Bond lengths and angles are in $\AA$ and degree, respectively.

$\mathrm{C}=\mathrm{O}$ bond length are $0.062,0.095$, and $0.116 \AA$ for the $1^{1} B_{g}, 1^{3} A_{g}$, and $1^{3} B_{u}$ states, respectively. The corresponding decrements in the $\mathrm{C}-\mathrm{C}$ bond length are $0.119,0.014$, and $0.141 \AA$, respectively. The $\mathrm{CCH}$ bond angles are increased by $4^{\circ}, 4.6^{\circ}$, and $5.3^{\circ}$, respectively, for these states, although the change of the $\mathrm{CCO}$ bond angles are comparatively small, $2^{\circ}, 2.2^{\circ}$, and $0.7^{\circ}$, respectively. For the doubly excited $2{ }^{1} A_{g}$ state, the general- $R$ optimization was performed and large relaxation energy was obtained, $1.77 \mathrm{eV}$. This is due to significant changes in the $\mathrm{C}=\mathrm{O}$ and $\mathrm{C}-\mathrm{C}$ bond lengths, by 0.117 and $0.156 \AA$, respectively. Large amount of energy lowering, 0.75 and $1.22 \mathrm{eV}$, due to geometry relaxation was also calculated for the $1^{3} A_{g}$ and $1^{3} B_{u}$ states, respectively. Similar trend was reported by the previous SAC-CI calculation $^{19}$ and CI calculations ${ }^{20,61}$ for the $1^{3} B_{u}$ state. On the other hand, the energy lowering for the $1{ }^{1} B_{g}$ states was small, although the geometry change was large. Good agreement was obtained for the adiabatic transition energy of the $1^{3} B_{g}$ state with the previous SAC-CI calculation. ${ }^{19}$ However, the present adiabatic transition energy deviates by $0.26 \mathrm{eV}$ from previous SAC-CI calculation for the $1{ }^{1} B_{g}$ state.

The $\mathrm{C}=\mathrm{O}$ bond length increases due to a reduction in bond order while the $\mathrm{C}-\mathrm{C}$ bond distance contracts and the $\mathrm{CCO}$ and $\mathrm{CCH}$ angles open. The $\mathrm{C}-\mathrm{H}$ bond lengths shrink in the excited states. To interpret these geometry changes using ESF theory, we have displayed, in Fig. 6, the electron density difference between the ground and excited states. For these excitations, the electron density in the $\mathrm{C}-\mathrm{C} \sigma$-bond region increases. As a result $\mathrm{EC}$ force increases along the $\mathrm{C}-\mathrm{C}$ bond, and the $\mathrm{C}-\mathrm{C}$ bond length decreases. On the other hand, in the $\mathrm{C}=\mathrm{O} \pi$-bond region, the electron density decreases and the $\mathrm{C}=\mathrm{O}$ bond length increases. Again the change of the electron density on $\mathrm{O}$ atoms results to a change of $\mathrm{AD}$ force. Hence, the $\mathrm{CCH}$ bond angles increases. A shrink in the $\mathrm{C}-\mathrm{H}$ bond lengths is also observed due the change of EC force. 
TABLE XII. Adiabatic excitation energy (in eV) for the excited states of s-trans glyoxal using [ $4 s 2 p 1 d / 2 s]$ $+[2 s 2 p](n=3)$ basis set.

\begin{tabular}{|c|c|c|c|c|c|c|c|c|}
\hline \multirow[b]{2}{*}{ State/nature } & \multicolumn{2}{|c|}{ SAC-CI } & \multicolumn{2}{|c|}{$\begin{array}{c}\mathrm{SAC}-\mathrm{CI}^{\mathrm{a}} \\
\text { (previous) }\end{array}$} & \multicolumn{2}{|c|}{$\mathrm{SCF}^{\mathrm{b}}$} & \multicolumn{2}{|c|}{$\mathrm{CI}^{\mathrm{c}}$} \\
\hline & Vertical & Adiabatic & Vertical & Adiabatic & Vertical & Adiabatic & Vertical & Adiabatic \\
\hline $2{ }^{1} A_{g}\left(V, n_{\mathrm{O}^{+}}\right)^{\mathrm{d}}$ & 5.66 & 3.89 & $\ldots$ & $\ldots$ & $\ldots$ & $\ldots$ & $\ldots$ & $\ldots$ \\
\hline $1{ }^{3} B_{g}^{8}\left(V, n_{\mathrm{O}^{+}}\right)$ & 4.05 & 4.03 & 4.97 & 4.3 & 5.75 & $\cdots$ & $\cdots$ & $\cdots$ \\
\hline $1{ }^{1} A_{u}^{s}\left(V, n_{\mathrm{O}^{+}}\right)$ & 3.04 & 3.06 & 3.53 & 3.36 & 3.92 & 3.85 & $\cdots$ & $\cdots$ \\
\hline $1{ }^{3} A_{g}\left(V, \pi_{\mathrm{C}=\mathrm{O}^{+}}\right)$ & 6.32 & 5.57 & $\cdots$ & $\cdots$ & $\cdots$ & $\cdots$ & $\cdots$ & $\cdots$ \\
\hline $1{ }^{3} B_{u}^{8}\left(V, n_{\mathrm{O}^{-}}\right)$ & 4.09 & 3.65 & 4.13 & 3.56 & 5.31 & 4.51 & 4.58 & 3.63 \\
\hline $1{ }^{3} A_{u}\left(V, n_{\mathrm{O}^{+}}\right)$ & 2.62 & 2.68 & 2.90 & 2.73 & 3.38 & 3.33 & 2.86 & 2.70 \\
\hline $1{ }^{3} B_{u}\left(V, \pi_{\mathrm{C}=\mathrm{O}^{-}}\right)$ & 5.23 & 4.01 & 5.43 & 3.77 & 4.09 & 1.84 & 5.11 & 3.12 \\
\hline
\end{tabular}

\section{THE $2{ }^{1} A_{g}$ STATE}

In this work, doubly excited states, so-called $2{ }^{1} A_{g}$ states, of these three molecules were investigated by the general- $R$ method. For butadiene, vertical excitation of this state has been intensively studied by some theoretical works. $^{30,31}$ The present calculation predicted the vertical transition energy of $6.56 \mathrm{eV}$, in agreement with other recent theoretical calculations such as MR-CCCI-PS, ${ }^{55}$ DC-MRSDCI, ${ }^{31}$ and MR-AQCC. ${ }^{30}$ It was important to include up to quadruple excitation operators in the general- $R$ calculation. For acrolein, the corresponding state was calculated in the higher energy region at $8.16 \mathrm{eV}$. The $2{ }^{1} A_{g}$ states

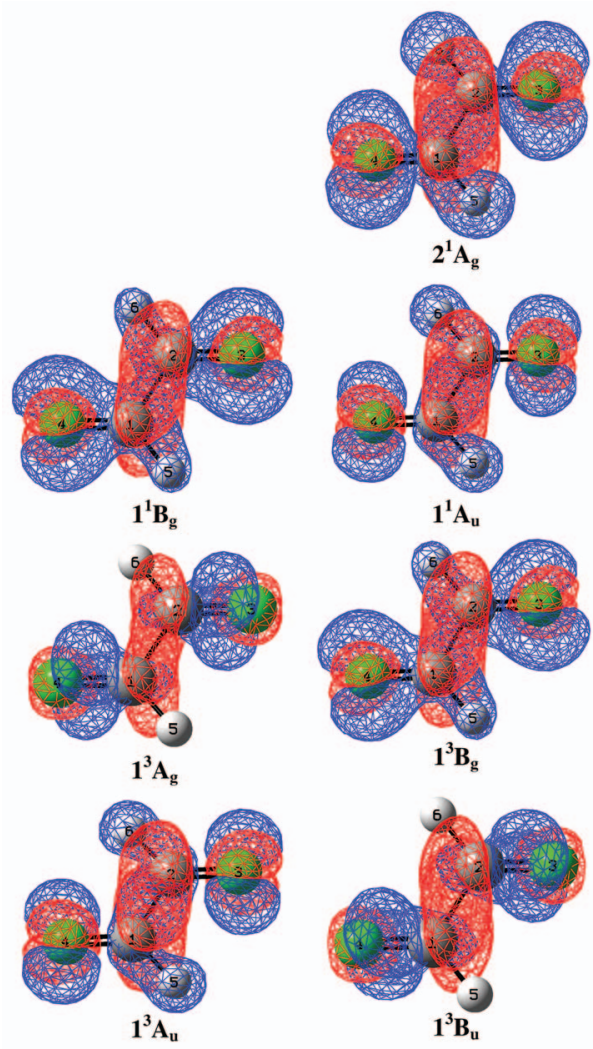

FIG. 6. (Color) SAC-CI electron density difference between the ground and excited states of s-trans glyoxal. Blue: decrement; red: increment (interval $=0.003$ ). of butadiene and acrolein were characterized as the $\pi \rightarrow \pi^{*}$ transition with moderate contributions by doubles whose SAC-CI coefficients are $\sim 0.3$. On the other hand, the $2{ }^{1} A_{g}$ state of glyoxal is characterized as pure $\left(n_{\mathrm{O}^{+}}, n_{\mathrm{O}^{+}} \rightarrow \pi^{*}, \pi^{*}\right)$ double excitation. This is because there is no singly excited state interacting with this state in the same energy region. This $2{ }^{1} A_{g}$ state of glyoxal was predicted to be very low at $5.66 \mathrm{eV}$, which is reasonable if we consider the $1{ }^{3} A_{u}$ state, $n_{\mathrm{O}^{+}} \rightarrow \pi^{*}$, exist at $2.63 \mathrm{eV}$. It should be noted that this is the first reliable theoretical calculation of this state to our best knowledge.

The equilibrium structures of these $2{ }^{1} A_{g}$ states for butadiene and glyoxal were also evaluated by the SAC-CI geometry optimization and the characteristic geometrical changes were predicted. For butadiene, the $\mathrm{CC}$ bond length of the $2{ }^{1} A_{g}$ state increases by $0.102 \AA$, which is much larger than other singlet states. The same is true for the $\mathrm{CO}$ bond length of glyoxal: the $\mathrm{CO}$ bond elongation was calculated to be $0.117 \AA$, while the CC bond length of this state shrinks by $0.156 \AA$. This large geometrical change is reasonable; the same change was obtained for the $1 A_{u}$ state, $n_{\mathrm{O}^{+}} \rightarrow \pi^{*}$ transition. The relaxation energies of these states were calculated to be very large, 1.18 and $1.77 \mathrm{eV}$ for butadiene and glyoxal, respectively, which are much larger than other singly excited states.

\section{COMPARISON OF THE EXCITED STATES}

The calculated excitation energies of vertical singlet and triplet transitions of butadiene, acrolein, and glyoxal are compared in Fig. 7. The valence ionized states are in the order of $\pi_{1}<\pi_{2}$ for butadiene, $n<\pi_{1}<\pi_{2}$ for acrolein, and $n^{+}<n^{-}<\pi_{1}<\pi_{2}$ for glyoxal in the increasing order of IPs. Therefore, for butadiene, the low-lying valence excited states are of $\pi \rightarrow \pi^{*}$ character, while for acrolein and glyoxal, the low-lying states are of $n \rightarrow \pi^{*}$ character. The transition energy of the lowest $\pi \rightarrow \pi^{*}$ excitation increases in the order of butadiene, acrolein, and glyoxal, reflecting the IPs of the lowest $\pi$ states. The correspondence of the $\pi \rightarrow \pi^{*}$ excitations among these molecules was shown by dotted lines in Fig. 7. In the case of acrolein and glyoxal, the $\pi \rightarrow \pi^{*}$ tran- 


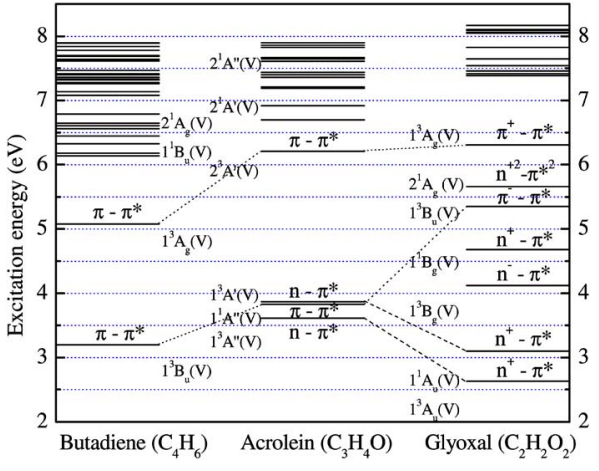

FIG. 7. Comparison among the lowest $\pi \rightarrow \pi^{*}$ and $n \rightarrow \pi^{*}$ transitions.

sitions correspond to the excitations from more deeply bound $\pi_{\mathrm{C}=\mathrm{O}}$ MOs. The lowest $n \rightarrow \pi^{*}$ transitions of glyoxal are lower in energy than that of acrolein.

\section{CONCLUSION}

The SAC-CI method has been successfully applied to calculate the electronic spectra and the excited-state geometries of 1,3-butadiene, acrolein, and glyoxal in their s-trans conformation. Theoretical spectra including valence and Rydberg excited states agree well with the experimental spectra and the detailed assignments were proposed with the analysis of second moment. The deviations of the vertical excitation energies from the experiment were less than $0.3 \mathrm{eV}$ for all cases. For the doubly excited states the general- $R$ calculations including up to quadruple excitations were performed. The calculated excitation energy of this $2{ }^{1} A_{g}$ state for butadiene is in good agreement with those of the recent calculations. The $2{ }^{1} A_{g}$ state of glyoxal was found to be pure double excitation: this is the first reliable theoretical prediction of this state.

The stable structures have been studied for some valence and Rydberg excited states in the planar structure. The optimized ground- and excited-state geometries agree well with the available experimental values; deviations lie within $0.03 \AA$ and $0.7^{\circ}$ for the bond lengths and angles, respectively. The geometry relaxation in valence excited states are as large as $\sim 0.1 \AA$ in $\mathrm{C}-\mathrm{C}$ and $\mathrm{C}=\mathrm{O}$ bond lengths and those of Rydberg excited states are about $\sim 0.05 \AA$. For doubly excited states, characteristic geometrical changes and large energetic relaxations were predicted. The force acting on the nuclei caused by the excitations has been discussed in detail by calculating the SAC-CI electron density difference between the ground and excited states; the geometry relaxation was well interpreted in the light of the electrostatic force theory.

\section{ACKNOWLEDGMENTS}

This study has been supported by the Grant for Creative Scientific Research from the Ministry of Education, Science and Sports of Japan. One of the authors (B.S.) is grateful to Japan Society for the Promotion of Science (JSPS) for the financial support. The authors thank Professor J. Paldus for the information on the experimental data that were studied in his papers.
${ }^{1}$ A. D. Walsh, Trans. Faraday Soc. 41, 498 (1945).

${ }^{2}$ W. C. Price and A. D. Walsh, Proc. R. Soc. London, Ser. A 174, 220 (1940).

${ }^{3}$ A. D. Walsh, Trans. Faraday Soc. 19, 1425 (1945).

${ }^{4}$ W. M. Flicker, O. A. Mosher, and A. Kuppermann, J. Chem. Phys. 59, 6502 (1973).

${ }^{5}$ W. M. Flicker, O. A. Mosher, and A. Kuppermann, Chem. Phys. 30, 307 (1978).

${ }^{6}$ J. P. Doering, J. Chem. Phys. 70, 3902 (1979).

${ }^{7}$ G. J. Verhaart and H. H. Brongersma, Chem. Phys. Lett. 72, 176 (1980).

${ }^{8}$ R. McDiarmid, Chem. Phys. Lett. 34, 130 (1975); A. Fahr and A. K. Nayak, Chem. Phys. 189, 725 (1994).

${ }^{9}$ J. P. Doering and R. McDiarmid, J. Chem. Phys. 73, 3617 (1980).

${ }^{10}$ R. McDiarmid, Chem. Phys. Lett. 188, 423 (1992).

${ }^{11}$ R. R. Chadwick, D. P. Gerrity, and B. S. Hudson, Chem. Phys. Lett. 115, 24 (1985).

${ }^{12}$ R. S. Becker, K. Inuzuka, and J. King, J. Chem. Phys. 52, 5164 (1970).

${ }^{13}$ M. Reguero, M. Olivucci, F. Bernardi, and M. A. Robb, J. Am. Chem. Soc. 116, 2103 (1994); K. W. Paulisse, T. O. Friday, M. L. Graske, and W. P. Polik, J. Chem. Phys. 113, 184 (2000); M. Olivucci, F. Bernardi, I. N. Ragazos, and M. A. Robb, J. Am. Chem. Soc. 115, 3710 (1993).

${ }^{14}$ A. C. P. Alves, J. Christoffersen, and J. M. Hollas, Mol. Phys. 20, 625 (1971).

${ }^{15}$ C. Fridh, L. Asbrink, and E. Lindholm, Phys. Scr. 20, 603 (1979).

${ }^{16}$ O. Kitao and H. Nakatsuji, Chem. Phys. Lett. 143, 528 (1988).

${ }^{17}$ S. Shih, R. J. Buenker, and S. D. Peyerimhoff, Chem. Phys. Lett. 16, 244 (1972).

${ }^{18}$ J. M. Leclerq, C. Mijoule, and P. Yvan, J. Chem. Phys. 64, 1464 (1976).

${ }^{19}$ K. Hirao, J. Chem. Phys. 79, 5000 (1983).

${ }^{20}$ C. E. Dykstra, R. R. Lucchese, and H. F. Schaefer III, J. Chem. Phys. 67, 2422 (1977)

${ }^{21}$ L. Serrano-Andres, M. Merchan, I. Nebot-Gill, R. Lindh, and B. O. Roos, J. Chem. Phys. 98, 3151 (1993).

${ }^{22}$ L. Serrano-Andres, B. O. Ross, and M. Merchan, Theor. Chim. Acta 87, 387 (1994).

${ }^{23}$ K. Nakayama, H. Nakano, and K. Hirao, Int. J. Quantum Chem. 66, 157 (1998).

${ }^{24}$ P. G. Szalay, A. Karpfen, and H. Lischka, Chem. Phys. 130, 219 (1989).

${ }^{25}$ R. J. Cave and E. R. Davidson, J. Chem. Phys. 91, 4481 (1987).

${ }^{26}$ C. E. Dykstra and H. F. Schaefer III, J. Am. Chem. Soc. 97, 7210 (1975).

${ }^{27}$ F. Aquilante, V. Barone, and B. O. Roos, J. Chem. Phys. 119, 12323 (2003).

${ }^{28}$ H. A. Witek, H. Nakano, and K. Hirao, J. Comput. Chem. 24, 1390 (2003).

${ }^{29}$ M. Boggio-Pasqua, M. J. Bearpark, M. Klene, and M. A. Robb, J. Chem. Phys. 120, 7849 (2004).

${ }^{30}$ M. Dallos and H. Lischka, Theor. Chem. Acc. 112, 16 (2004).

${ }^{31}$ J. Lappe and R. J. Cave, J. Phys. Chem. A 104, 2294 (2000).

${ }^{32}$ T. Nakajima and H. Nakatsuji, Chem. Phys. Lett. 280, 79 (1997); Chem. Phys. 242, 177 (1999).

${ }^{33}$ M. Ishida, K. Toyota, M. Ehara, and H. Nakatsuji, Chem. Phys. Lett. 347, 493 (2001).

${ }^{34}$ R. Shepard, H. Lischka, P. G. Szalay, T. Kovar, and M. Ernzerhof, J. Chem. Phys. 96, 2085 (1992); H. Lischka, M. Dallos, and R. Shepard, Mol. Phys. 100, 1647 (2002)

${ }^{35}$ Y. Luo, H. Ågren, and S. Stafström, J. Chem. Phys. 98, 7782 (1994).

${ }^{36}$ E. Hollauer and M. A. C. Nascimento, Chem. Phys. Lett. 181, 463 (1991).

${ }^{37}$ D. W. Turner, Molecular Photoelectron Spectroscopy (WileyInterscience, New York, NY, 1970).

${ }^{38}$ U. Pincelli, B. Cadloli, and D. J. David, J. Mol. Struct. 9, 173 (1971); T. Ha, ibid. 12, 171 (1972).

${ }^{39}$ H. Nakatsuji, Chem. Phys. Lett. 59, 362 (1978).

${ }^{40}$ H. Nakatsuji, Chem. Phys. Lett. 67, 329 (1979).

${ }^{41}$ H. Nakatsuji, Acta Chim. Hung. 129, 719 (1992); Computational Chemistry-Review of Current Trends (World Scientific, Singapore, 1997); M. Ehara, J. Hasegawa, and H. Nakatsuji, Theory and Applications of Computational Chemistry: The First 40 Years, edited by C. E. Dykstra, G. Fenking, K. S. Kim, and G. E. Scuseria (Elsevier, Holland, 2005).

${ }^{42}$ M. Ehara, M. Ishida, K. Toyota, and H. Nakatsuji, Reviews in Modern Quantum Chemistry, edited By K. D. Sen (World Scientific, Singapore, 2002); M. Ishida, K. Toyota, M. Ehara, M. J. Frisch, and H. Nakatsuji, J. Chem. Phys. 120, 2593 (2004). 
${ }^{43}$ H. Nakatsuji, J. Am. Chem. Soc. 95, 345 (1973); H. Nakatsuji and T. Koga, The Force Concept in Chemistry, edited by B. M. Deb (Van Nostrand Reinhold, New York, 1981).

${ }^{44}$ T. H. Dunning, J. Chem. Phys. 53, 2823 (1970).

${ }^{45}$ T. H. Dunning and P. J. Hay, Methods of Electronic Structure Theory (Plenum, New York, 1977).

${ }^{46}$ H. Nakatsuji, Chem. Phys. 75, 425 (1983).

${ }^{47}$ Structure Data of Free Polyatomic Molecules, Landolt-Bornstein, New Series, Group II, Vol. 7 (Springer, Berlin, 1976).

${ }^{48}$ H. Nakatsuji, Chem. Phys. Lett. 177, 331 (1991).

${ }^{49}$ M. J. Frisch, G. W. Trucks, H. B. Schlegel et al., Gaussian 03, Gaussian, Inc., Pittsburgh, PA, 2003.

${ }^{50}$ K. Kimura, S. Katsumata, Y. Achiba, and S. Iwata, Handbook of Helium(He I) Photoelectron Spectra of Fundamental Organic Molecules. Ionization Energies, ab initio Assignments, and Valence Electronic Structure for 200 Molecules (Japan Scientific Societies, Tokyo, Japan, 1981).

${ }^{51}$ B. Ostojic and W. Domcke, Chem. Phys. 269, 1 (2001).

${ }^{52}$ C.-P. Hsu, S. Hirata, and M. Head-Gordon, J. Phys. Chem. A 105, 451 (2001).

${ }^{53}$ J. P. Doering and R. McDiarmid, J. Chem. Phys. 75, 2477 (1981).

${ }^{54}$ R. R. Chadwick, D. P. Gerrity, and B. S. Hudson, J. Chem. Phys. 95, 7204 (1991).

${ }^{55}$ L. Serrano-Andres, J. Sanchez-Mann, and I. Nebot-Gil, J. Chem. Phys. 97, 7499 (1992).

${ }^{56}$ C. R. Brundle and M. B. Robin, J. Am. Chem. Soc. 92, 5550 (1970).

${ }^{57}$ R. J. Buenker, S. Shih, and S. D. Peyerimhoff, Chem. Phys. Lett. 44, 385 (1976).

${ }^{58}$ A. G. Robinson, P. R. Winter, and T. S. Zwier, J. Chem. Phys. 116, 7918 (2002).

${ }^{59}$ C. S. Page and M. Olivucci, J. Comput. Chem. 24, 298 (2003).
${ }^{60}$ B. S. Hudson, B. E. Kohler, and K. Schulten, In Excited States (Academic, New York, 1982).

${ }^{61}$ C. E. Dykstra and H. F. Schaefer III, J. Am. Chem. Soc. 98, 401 (1976).

${ }^{62}$ C. E. Bolm and A. Bauder, Chem. Phys. Lett. 88, 55 (1982).

${ }^{63}$ O. Kitao and H. Nakatsuji, J. Chem. Phys. 87, 1169 (1987); J. Wan, J. Meller, M. Hada, M. Ehara, and H. Nakatsuji, ibid. 113, 7853 (2000); J. Wan, M. Hada, M. Ehara, and H. Nakatsuji, ibid. 114, 842 (2001).

${ }^{64}$ J. M. Hollas, Spectrochim. Acta 19, 1425 (1963).

${ }^{65}$ M. Ehara, M. Nakata, and H. Nakatsuji, Mol. Phys. 104, 971 (2006).

${ }^{66}$ H. L. McMurry, J. Chem. Phys. 9, 231 (1941).

${ }^{67}$ G. Mackinney and O. Temmer, J. Am. Chem. Soc. 70, 3586 (1948).

${ }^{68}$ W. Hug, J. Kuhn, K. J. Seibold, H. Labhart, and G. Wag-niere, Helv. Chim. Acta 54, 1451 (1971)

${ }^{69}$ M. B. Robin, Higher Excited States of Polyatomic Molecules (Academic, New York, 1975)

${ }^{70}$ A. D. Walsh, Trans. Faraday Soc. 42, 66 (1946).

${ }^{71}$ H. Kato, H. Konishi, H. Yamabe, and T. Yonezawa, Bull. Chem. Soc. Jpn. 40, 2761 (1967).

${ }^{72}$ G. Herzberg, Molecular Spectra and Structure III. Electronic Spectra and Electronic Structure of Polyatomic Molecules (Van Nostrand, New York, 1966).

${ }^{73}$ J. C. D. Brand, Trans. Faraday Soc. 50, 431 (1954).

${ }^{74}$ J. Paldus and D. A. Ramasay, Can. J. Phys. 45, 1389 (1967).

${ }^{75}$ F. W. Briss, B. D. Braund, A. R. H. Cole, R. Engleman, A. A. Green, S. M. Jarpar, R. Nanes, B. J. Orr, D. A. Ramsay, and J. Szyszka, Can. J. Phys. 55, 390 (1977).

${ }^{76}$ J. F. Stanton and J. Gauss, Spectrochim. Acta 53, 1153 (1997).

${ }^{77}$ B. F. Minaev, D. Jonsson, and H. Å. P. Norman, Chem. Phys. 194, 19 (1995).

${ }^{78}$ E. Drent and J. Kommandeur, Chem. Phys. Lett. 14, 321 (1972). 